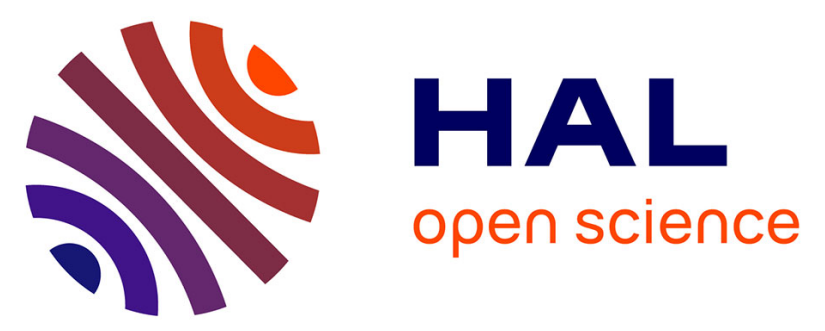

\title{
Multiscale Approach to the Dissociative Adsorption of Oxygen on a Highly Dispersed Platinum Supported on $\gamma$-Al2O3
}

Alexis Sangnier, Mickaël Matrat, Andre Nicolle, Christophe Dujardin, Céline Chizallet

\section{To cite this version:}

Alexis Sangnier, Mickaël Matrat, Andre Nicolle, Christophe Dujardin, Céline Chizallet. Multiscale Approach to the Dissociative Adsorption of Oxygen on a Highly Dispersed Platinum Supported on $\gamma$ Al2O3. Journal of Physical Chemistry C, 2018, 122 (47), pp.26974-26986. 10.1021/acs.jpcc.8b09204 . hal-01958217

\section{HAL Id: hal-01958217 \\ https://hal-ifp.archives-ouvertes.fr/hal-01958217}

Submitted on 17 Dec 2018

HAL is a multi-disciplinary open access archive for the deposit and dissemination of scientific research documents, whether they are published or not. The documents may come from teaching and research institutions in France or abroad, or from public or private research centers.
L'archive ouverte pluridisciplinaire HAL, est destinée au dépôt et à la diffusion de documents scientifiques de niveau recherche, publiés ou non, émanant des établissements d'enseignement et de recherche français ou étrangers, des laboratoires publics ou privés. 


\section{A Multi-Scale Approach to the Dissociative}

${ }^{1}$ Powertrain and Vehicle Division, IFP Energies Nouvelles - 1 et 4 avenue de Bois-Préau - 92852 RueilMalmaison Cedex, (France) ; Institut Carnot IFPEN Transports Energies 


\section{ABSTRACT.}

The understanding of the reactivity of supported platinum with oxygen is of paramount relevance in heterogeneous catalysis, inter alia. We present here a multi-scale investigation of the interaction of highly dispersed $\mathrm{Pt} / \gamma-\mathrm{Al}_{2} \mathrm{O}_{3}$ catalysts with $\mathrm{O}_{2}$, through the combination of TPD (Temperature-Programmed Desorption) experiments, ab initio simulations on a model $\mathrm{Pt}_{13} / \gamma$ $\mathrm{Al}_{2} \mathrm{O}_{3}$ cluster, and kinetic simulations of the TPD thanks to data obtained ab initio. The specific behavior of the sub-nanometric platinum particles is benchmarked against the one of the ideal $\operatorname{Pt}(111)$ surface, as predicted by similar ab initio - based kinetic modeling. This approach reveals a fully different reactivity of highly-dispersed Pt nanoparticles with respect to $\mathrm{Pt}(111)$, with a much higher capacity of oxygen storage for given temperature and $\mathrm{P}\left(\mathrm{O}_{2}\right)$ conditions. In a large operating conditions interval, the $\mathrm{Pt}_{13}$ clusters are converted in an oxide, the stoichiometry of which is close to $\mathrm{PtO}_{2}$, but with a very specific hemispherical shape. $\mathrm{Pt}_{\text {cluster }}-\mathrm{O}_{\text {alumina }}$ and $\mathrm{O}_{\text {cluster- }}-\mathrm{Al}_{\text {alumina }}$ bonds ensure a very strong interaction of these clusters with the support. The kinetic scheme built upon $a b$ initio data to simulate TPD experiments allows to attribute the highest desorption temperatures reached experimentally to highly dispersed particles, from $\mathrm{Pt}_{13} \mathrm{O}_{20}$ to $\mathrm{Pt}_{13} \mathrm{O}_{4}$ clusters, through $\mathrm{Pt}_{13} \mathrm{O}_{16}$ and $\mathrm{Pt}_{13} \mathrm{O}_{10}$ intermediates. 


\section{Introduction}

Platinum is a widely used active phase in heterogeneous catalysis due to its intrinsic activity for hydrogenation/dehydrogenation reactions as well as its redox properties. ${ }^{1-4}$ It is involved in many environmental, refining and petrochemical applications. ${ }^{5-8}$ Concerning automotive applications, post-treatment devices contain different metals such as rhodium, palladium and platinum enabling the oxidation of hydrocarbons and carbon monoxide in $\mathrm{CO}_{2} \cdot{ }^{9}$ Platinum also contributes to the conversion of chemical energy into electricity assisting the hydrogen oxidation to water in fuel cells. ${ }^{10-13}$ Platinum is also involved into $\mathrm{CO}$ conversion to $\mathrm{CO}_{2}$ and $\mathrm{H}_{2}$ through the well-known water-gas shift reaction. ${ }^{9}$ Recently EU listed platinum as critical material since the supply of the platinum group metals (PGMs) is still relatively concentrated within few countries. ${ }^{14}$ The optimization of high dispersions is a way to reduce practically the use of PGMs.

Understanding the catalyst structuration effect on its reactivity and selectivity is then decisive. In particular, size effects play a huge role in many properties of nanoparticles, with respect to bulk materials. ${ }^{15-17,18}$ These effects are also expected to vary significantly according to the environment of the catalyst, such as the nature of the support or the nature of the gas. For example, the $\operatorname{Pt}(111)$ surface is considerably changing in the presence of $\mathrm{O}_{2}$, from dissociative adsorption on hollow fcc sites ${ }^{19-23}$ to $\mathrm{PtO}_{2}$ layers, ${ }^{24-26}$ or, depending on temperature and $\mathrm{O}_{2}$ partial pressure, to more special surface structures such as triangles, ${ }^{27}$ honeycombs ${ }^{28}$ or spoke wheels. ${ }^{29}$ A structure effect of platinum for interaction of $\mathrm{O}_{2}$ is already known: in the case of $\operatorname{Pt}(321)$ and $\operatorname{Pt}(211)$, the presence of steps or adatoms influences the adsorption of oxygen. ${ }^{30-31}$ These atoms facilitate the adsorption at low coverage and lead to higher heats of adsorption than $\operatorname{Pt}(111)$. The particle size was also shown 
to have a drastic impact on oxygen retention for supported platinum catalysts, playing a major role 2 in structure sensitive oxidation reactions. ${ }^{32-34}$

In the present work, we focus on the interaction of $\mathrm{O}_{2}$ with the $\mathrm{Pt} / \gamma-\mathrm{Al}_{2} \mathrm{O}_{3}$ system, starting from well-dispersed catalysts with subnanometric metallic particle sizes. This is of interest for all the applications where platinum is used in oxidizing environment, such as for oxidation reactions, but also considering that most reduced platinum catalysts were obtained first in an oxidic form, after impregnation, drying and possible calcination. ${ }^{35}$ Moreover, adsorption of oxygen on platinum particles is also a way to investigate the dispersion of a catalyst. ${ }^{36-39}$ Gamma alumina is a versatile non-reducible support, often chosen at the industrial and laboratory scale for its high surface area and significant surface reactivity, ${ }^{40}$ allowing for the dispersion of small metallic particles, if not Single Atom Catalysts. ${ }^{41-44}$ Our aim is to get an atomic-scale insight in the surface structures described by the ultra-dispersed $\mathrm{Pt} / \gamma-\mathrm{Al}_{2} \mathrm{O}_{3}$ system in the presence of $\mathrm{O}_{2}$, and in the strength of the corresponding interaction.

$A b$ initio modeling appears as a relevant tool for the investigation of well-dispersed platinum particles on various oxides, in particular $\gamma-\mathrm{Al}_{2} \mathrm{O}_{3} \cdot{ }^{12,45-46}$ Thanks to Density Functional Theory (DFT) calculations, small non-supported aggregates from $\mathrm{Pt}_{2}$ to $\mathrm{Pt}_{20}{ }^{47-50}$ were shown to reconstruct easily upon $\mathrm{O}_{2}$ adsorption, which makes the adsorption strongly favorable. The preferred adsorption mode on these structures is the bridge one. For particles larger than $\mathrm{Pt}_{35}{ }^{51}$ regular facets such as $\operatorname{Pt}(111)$ or $\operatorname{Pt}(100)$ surfaces can be identified, contrary to the very distorted morphology of the smallest clusters. ${ }^{52-53}$ The heat of adsorption of oxygen on the facets is of the same order of magnitude as for the extended surfaces alone. The adsorption of atomic oxygen however appears to be preferred at the intersections of these facets such as edges and corners, thanks to the low-coordinated platinum at edges combined with platinum atoms mobility. 
Systematic DFT calculations for clusters of variable size show that size effect is substantial for the adsorption of oxygen below about 150 atoms. ${ }^{54}$ While many DFT studies deal with the adsorption of oxygen on flat or corrugated platinum surfaces, ${ }^{20-21,26,30,55-60}$ studies taking into account the support effect on the interaction of oxygen with platinum clusters are much scarcer, and generally concern very small clusters or single atoms, and a single $\mathrm{O}_{2}$ molecule. ${ }^{47,61-62}$ A systematic investigation of the interaction of oxygen with sub-nanometric platinum cluster, typically $\mathrm{Pt}_{13}$, supported on $\gamma-\mathrm{Al}_{2} \mathrm{O}_{3}$, taking into account the effect of $\mathrm{O}$ coverage, function of the temperature and $\mathrm{O}_{2}$ partial pressure, and possible reconstructions, is thus needed. The approach previously undertaken in the case of hydrogen interaction with $\mathrm{Pt}_{13} / \gamma-\mathrm{Al}_{2} \mathrm{O}_{3}$, revealing strong reconstructions of the metallic phase and modulation of the metal - support interaction upon variation of the $\mathrm{H}$ coverage, ${ }^{41,63}$ is worth being extended to oxygen.

In the present work, we propose to combine ab initio periodic calculations and $\mathrm{O}_{2}$ Temperature-Programmed Desorption (TPD) measurements, the respective consistency of which will be evaluated thanks to kinetic modeling, based on the ab initio data, through a multi-scale simulation approach. While such an approach turned out to be successful in the case of oxygen desorption from $\operatorname{Pt}(111)^{58}$ and for many other chemical systems, ${ }^{64-75}$ it was never demonstrated for the interaction of oxygen with the ultra-dispersed $\mathrm{Pt} / \gamma-\mathrm{Al}_{2} \mathrm{O}_{3}$ system so far. First, a systematic structural investigation is provided for $\mathrm{O}_{2}$ dissociative adsorption on $\mathrm{Pt}_{13} / \gamma-\mathrm{Al}_{2} \mathrm{O}_{3}(100)$, for a number of oxygen atoms pre cluster ranging from 1 to 32 , thanks to ab initio molecular dynamics. Our own calculations on the $\operatorname{Pt}(111)$ surface allow the comparison with highly dispersed platinum using the same approach. Thermodynamic and kinetic data are extracted from these ab initio models, which allows us to build a kinetic model to simulate the TPD experiments. This 
multiscale approach a full assignment of the experimental feature in terms of particle size and $2 \quad$ oxygen coverage.

\section{Methods and experimental details}

\subsection{Ab initio calculations}

Structure optimizations were performed with the Vienna Ab initio Simulation Package (VASP). ${ }^{76-77}$ A plane-wave basis set using the Projector-Augmented Wave $(\mathrm{PAW})^{78}$ was employed. The GGA-Perdew-Burke-Erzenhof exchange correlation functional ${ }^{79}$ was used for the whole study. The cut-off energy for the plane-wave basis was set to $400 \mathrm{eV}$. Gaussian smearing with $\sigma=0.02 \mathrm{eV}$ was used for the supported clusters. The electronic optimizations were done up to a convergence of $10^{-6} \mathrm{eV}$ for the self-consistent loop, and geometries were optimized until all forces on atoms were lower than $0.02 \mathrm{eV} / \AA$. Dipolar correction was added in the direction perpendicular to the slab. Bader charges ${ }^{80-81}$ were calculated at the same level of theory.

For the cluster system, we chose the dehydrated $\gamma-\mathrm{Al}_{2} \mathrm{O}_{3}(100)$ surface model of Digne et al. as the support model. ${ }^{82-83}$ Indeed, from previous studies about monometallic or bimetallic catalysts, models involving $\gamma-\mathrm{Al}_{2} \mathrm{O}_{3}(100)$ dehydrated surface as a first approach, already provided fruitful detailed information. ${ }^{41,45,53,63,84}$ A two platinum-layers $\mathrm{Pt}_{13}$ structure was found the most stable on this alumina facet. ${ }^{53}$ The box dimensions $\left(16.71 \times 16.79 \times 21.80 \AA^{3}\right)$ were chosen in order to avoid lateral interactions between periodic cluster images. Periodic slabs consist of four alumina layers separated by a vacuum thickness corresponding to more than two equivalent empty layers. The two topmost alumina layers were relaxed, as well as all metallic atoms, whereas the two other alumina ones were frozen. Calculations were performed at the $\Gamma$ point. For the $\operatorname{Pt}(111)$ model, a 
$3 \times 3$ five-layer slab model was used, with a K-points grid of $5 \times 5 \times 1$. The top three layers were 2 relaxed while the two other ones were frozen. The adsorption energies of atomic oxygen were calculated per $\mathrm{O}_{2}$ molecule, according to equation 1. The energy of $\mathrm{O}_{2}\left(E_{\mathrm{O}_{2}}\right)$ was calculated by placing a $\mathrm{O}_{2}$ molecule into a $15 \times 15 \times 15 \AA^{3}$ box.

$$
E_{\text {adsorption }}=\frac{2}{n}\left(E_{P t\{i\} O_{n}}-E_{P t\{i\}}-\frac{n}{2} E_{O_{2}}\right)
$$
$\mathrm{n}$ is the number of oxygen adsorbed per cell on $\mathrm{Pt}_{13}$ or $\operatorname{Pt}(111), E_{P t\{i\} o_{n}}$ and $E_{P t\{i\}}$ the electronic energies of the system considered with or without adsorbed oxygen respectively (supported $\mathrm{Pt}_{13}$ cluster or $\mathrm{Pt}(111)$ surface). Energies presented in this work are displayed in $\mathrm{kcal}^{\mathrm{mol}}{ }^{-1}$ per $\mathrm{O}_{2}$ molecule, and are computed negatively when the reaction is favorable. In the case of $n>2$, equation 1 gives the arithmetic mean adsorption energy per $\mathrm{O}_{2}$.

In the case of the supported $\mathrm{Pt}_{13}$ cluster, with a number of oxygens higher than one, four geometries were first optimized to determine the most stable one. The latter was then refined by velocity scaled molecular dynamics (MD) at $600 \mathrm{~K}$, with a time-step of 5 femtoseconds over 1500 steps, the whole alumina support being frozen for such calculations. In the course of the dynamics, very significant geometry changes were observed for most stoichiometries, sometimes with reconstruction of the cluster (Supporting Information S1). The three most stable geometries obtained during the MD run were then chosen to be quenched by performing a structure optimization calculation with the same characteristics as previously detailed.

For the alumina supported cluster model, the interaction energy between support and platinum cluster was calculated by equation 2 .

$$
E_{\text {interaction }}=\left(E_{P t_{13} O_{n} / \gamma-A l_{2} O_{3}}-E_{P t_{13} O_{n}}^{*}-E_{\gamma-A l_{2} O_{3}}^{*}\right)
$$


with single point calculations (referred to as a star superscript) for the separate cluster and 2 support systems at the geometry of the supported system.

The thermodynamic diagram was built from the most stable quenched geometries obtained after molecular dynamics. Vibrational parts of the enthalpy and entropy were determined by an harmonic frequency analysis. This was performed with a displacement of \pm 0.01 Angström in each matrix was then calculated by the finite difference method. The entropy of this condensed phase was assumed to result only from its vibrational part neglecting rotational and translational degrees of freedom. The calculation of the free energy for each system was done using the equations reported in Supporting Information S2. The oxygen-adsorption free energy $G_{\text {adsorption }}$ (cumulated over all adsorbed oxygen molecules) used to build the thermodynamic diagrams is given in equation 3. The different domain of coverages present on the diagrams reflects the minimum free energy among other coverage systems.

$$
G_{\text {adsorption }}\left(p_{O_{2}}, T, \theta_{O_{2}}\right)=\left(G_{P t_{13} O_{n}}\left(T, \theta_{O_{2}}\right)-G_{P t_{13}}(T)-\frac{n}{2} G_{O_{2}}\left(p_{O_{2}}, T\right)\right)
$$

Concerning the transition states identification for the dissociation of adsorbed $\mathrm{O}_{2}$, the NEB method (Nudge Elastic Band) of VASP was used ${ }^{85}$ The convergence criterion for the relaxation loop was set to $0.02 \mathrm{eV} / \AA$. The initial guess for eight intermediate images was determined by Opt'n Path ${ }^{86}$ via a cartesian translation of the atoms from the initial to the final state. After completion of the NEB optimization, a quasi-newtonian ${ }^{87}$ calculation was performed on the image that was the closest to the transition state. A vibrational calculation was finally done to validate the transition structure, with a single imaginary vibrational mode corresponding to the reaction studied. 


\subsection{Kinetic modeling}

The Chemkin Pro ${ }^{\circledR}$ software ${ }^{88}$ was used to simulate TPD experiments ab initio thermokinetic data. A perfectly stirred reactor was used as the reactor peclet number was much lower than unity. Thiele and mass Biot numbers were found to be also much lower than one, highlighting the occurrence of kinetic regime. Hence, the diffusion phenomena of gas species to the surface were not taken into account.

The reaction mechanisms was built by including successive dissociative adsorption reactions of one molecule of $\mathrm{O}_{2}$ according to equations 4 and 5. Each direct and reverse reactions are listed, up to 32 oxygen atoms for $\mathrm{Pt}_{13}$ and $1 \mathrm{ML}$ (monolayer) for $\mathrm{Pt}(111)$.

$$
k_{\text {adsorption }}=\frac{s}{\Gamma_{\text {tot }}{ }^{m}} \sqrt{\frac{R T}{2 \pi M_{O_{2}}}} \exp \left(-\frac{E_{\text {dissociation }}}{R T}\right)
$$

Notably, such a mean-field model does not take into account the need to have two neighbouring sites for $\mathrm{O}_{2}$ dissociation into two atomic oxygen. Such a need was shown recently in ref. ${ }^{89}$ This approach also does not indeed take into account surface species transport phenomenon, such as 
migration. Taking all these aspects into account would require a kinetic Monte Carlo simulation, 2 for example, which is beyond the scope of the present work. Likely, the rates evaluated in the present work might be overestimated due to the absence of condition to have two neighboring free sites in the model. Part of the gap between the model and reality may be compensated by the choice of sticking factor values, for which we do not have any accurate experimental determination.

To account for coverage dependent dissociation energy, a linear law was applied to the dissociation energies found for $\operatorname{Pt}(111)$, whereas piecewise linear trends were applied to the three ab initio dissociation energies investigated on the $\mathrm{Pt}_{13}$ cluster (see later, section 4.3).

Thermodynamic consistency was guaranteed by equation 7 , with $\Delta_{r} H_{\text {desorption }}$ and $\Delta_{r} S_{\text {desorption }}$ the average enthalpy and entropy of the desorption reaction, determined between $300 \mathrm{~K}$ and $1000 \mathrm{~K}$ with $a b$ initio simulations between two consecutive oxygen coverage structures.

$$
k_{\text {desorption }}=k_{\text {adsorption }} \times \exp \left(-\frac{\Delta_{r} H_{\text {desorption }}-T \Delta_{r} S_{\text {desorption }}}{R T}\right)
$$

Few studies investigated the sticking coefficient of $\mathrm{O}_{2}$ on $\mathrm{Pt}(111),{ }^{22,90-91}$ however it was shown to vary strongly with $\mathrm{O}_{2}$ partial pressure and temperature. No temperature deviation from the setpoint were detected experimentally implying that the endothermic effect due to desorption may be neglected.

The desorption rate constants were fitted to the Arrhenius-Kooij formalism represented by equation 8 .

$$
k=\mathrm{A} \times T^{\beta} \times \exp \left(-\frac{E_{\text {activation }}}{R T}\right)
$$


$A, \beta$ and $E_{\text {activation }}$ denote respectively the pre-exponential factor, the temperature exponent and 2 the activation energy (in kcal.mol ${ }^{-1}$ ).

\subsection{Experiments}

\section{a. Preparation of the catalysts}

Ultra-dispersed platinum catalysts were obtained by impregnation of a $\mathrm{H}_{2} \mathrm{PtCl}_{6}$ solution (STREM Chemical, 99.9 wt $\%$ purity, concentration adjusted to reach $0.3 \mathrm{wt} \%$ and $1 \mathrm{wt} \% \mathrm{Pt}$ ) on $\gamma-\mathrm{Al}_{2} \mathrm{O}_{3}$ (BET surface equal to $200 \mathrm{~m}^{2} \cdot \mathrm{g}^{-1}$, obtained from the calcination of a SB3 boehmite gel from SASOL, same protocol as in ref. ${ }^{92}$ ), followed by drying at $120^{\circ} \mathrm{C}$ overnight, and calcination at $520^{\circ} \mathrm{C}$ under dry air $\left(1 \mathrm{~L} \cdot \mathrm{g}^{-1} \cdot \mathrm{h}^{-1}\right)$ for $2 \mathrm{~h}$, dechlorination by a wet air flow $\left(8000 \mathrm{ppm} \cdot \mathrm{h}^{-1}\right.$ water $)$ at $520^{\circ} \mathrm{C}$. The dechlorinated samples were finally reduced under $\mathrm{H}_{2}$ flow $\left(1 \mathrm{~L} \cdot \mathrm{g}^{-1} \cdot \mathrm{h}^{-1}, 2 \mathrm{~h}\right)$ at $500^{\circ} \mathrm{C}$.

\section{b. Characterizations}

The catalysts were characterized by X-ray fluorescence (Thermo scientific ARL Perform'X) to determine the final platinum and chlorine content. The results are presented in Supporting Information S3 and show that the expected compositions are reached (close to $0.3 \mathrm{wt} \%$ and $1 \mathrm{wt}$ $\%$ for platinum, low chlorine loadings).

Platinum dispersion on alumina was determined by hydrogen titration of chemisorbed oxygen $\left(\mathrm{H}_{2}-\mathrm{O}_{2}\right.$ titration) in a Gira Xsorb apparatus with a thermal conductivity detector. The samples were first calcined under air at $530^{\circ} \mathrm{C}$ for two hours at $10^{\circ} \mathrm{C} \mathrm{min}^{-1}$. The sample then was cooled down to room temperature and purged with $\mathrm{He}$. The first reduction with $\mathrm{H}_{2}$ was done at $450^{\circ} \mathrm{C}$ for two hours with a flow of $87 \mathrm{NmL} \mathrm{min}^{-1}$ and a ramp of $5^{\circ} \mathrm{C} \mathrm{min}^{-1}$. After cooling down to room temperature and purging with $\mathrm{He}$, pulses with pressures from 0.5 to $60 \mathrm{kPa}$ of oxygen were added until saturation occurred at $35^{\circ} \mathrm{C}$. This process was repeated once. 
HAADF-STEM (High angle annular dark field - scanning transmission electron microscopy) experiments were performed on a STEM/TEM JEOL 2100F microscope operating at $200 \mathrm{kV}$ with a spot size of $0.5 \mathrm{~nm}$. The reduced catalyst sample was grinded, suspended in ethanol and sonicated. A drop of the resulting suspension was deposited on a copper grid coated with a holeycarbon film, and the alcohol was evaporated.

\section{c. $\mathrm{O}_{2}$ Temperature-Programmed Desorption}

The TPD experiments were performed with a Micromeritics (Autochem II 2920) set-up. The oxygen release was quantified with a mass spectrometer (Pfeiffer QMS 200). Experiments consisted in three steps with a total gas flow set to $50 \mathrm{~mL} \cdot \mathrm{min}^{-1}$ : (1) a pre-treatment step at $600^{\circ} \mathrm{C}$ during five hours with helium enables to remove adsorbed water as well as to clean the surface from adsorbates present on the catalyst and on the metal oxide; (2) a contact step with $\mathrm{O}_{2}$ (mixture of $5 \% \mathrm{v} / \mathrm{v} \mathrm{O}_{2} / \mathrm{He}$ ) during one hour at $100^{\circ} \mathrm{C}$; (3) finally, the release of molecular oxygen is followed during the increase of temperature with a ramp of $5^{\circ} \mathrm{C} / \mathrm{min}$ using helium as carrier gas. The temperature and duration of the pre-treatment step were optimized after analysis of the behaviour of the $1 \mathrm{wt} \% \mathrm{Pt} / \gamma-\mathrm{Al}_{2} \mathrm{O}_{3}$ material (Supporting Information $\mathrm{S} 4$ ). The mass spectrometry signals of $\mathrm{O}_{2}$ for alumina alone was moreover substracted from that of the catalysts obtained with the same treatment conditions, to extract the contribution of the metallic particles alone.

\section{Experimental results}

\subsection{Dispersion of platinum nanoparticles}


The platinum nanoparticles supported on $\mathrm{Al}_{2} \mathrm{O}_{3}$ were characterized after synthesis and reduction 2 with scanning tunneling electronic microscopy. Figure 1 presents the picture recorded for the 0.3 3 and the $1 \mathrm{wt} \%$ platinum fresh catalyst.

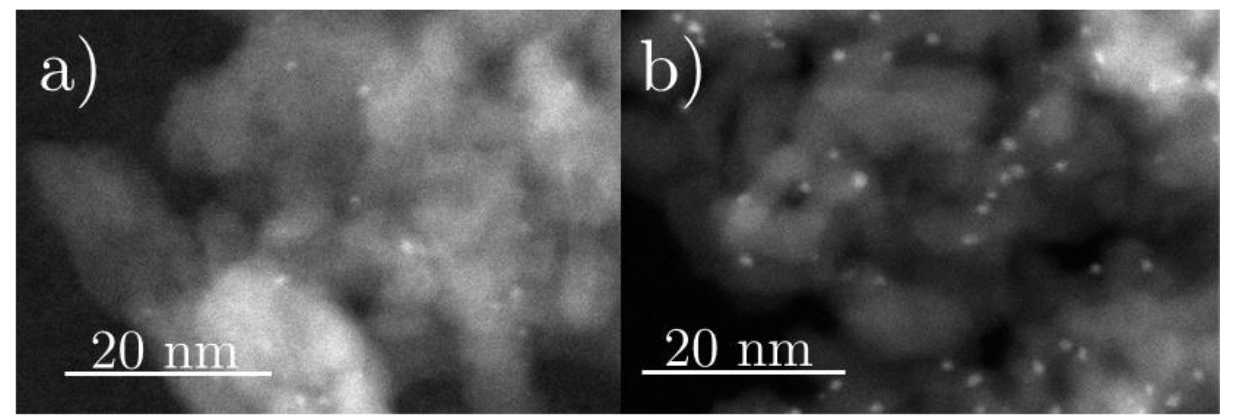

Figure 1 : Scanning tunneling electronic microscopy of the fresh a) $0.3 \mathrm{wt} \% \mathrm{Pt} / \gamma-\mathrm{Al}_{2} \mathrm{O}_{3}$ and b) $1 \mathrm{wt} \%$ $\mathrm{Pt} / \gamma-\mathrm{Al}_{2} \mathrm{O}_{3}$ catalyst after dechlorination.

The average particle size is $0.85 \pm 0.18 \mathrm{~nm}$ and $1.07 \pm 0.17 \mathrm{~nm}$ respectively for 0.3 and $1 \mathrm{wt} \%$ $\mathrm{Pt} / \gamma-\mathrm{Al}_{2} \mathrm{O}_{3}$ catalysts (Figure 2), underlining the formation of highly-dispersed nanoparticles supported on alumina. The average particle size corresponds to about ten-atoms platinum particle. Moreover the $\mathrm{H}_{2} / \mathrm{O}_{2}$ titration performed gives a 0.98 and 0.90 dispersion respectively for the 0.3 wt $\%$ and 1 wt $\% \mathrm{Pt} / \gamma-\mathrm{Al}_{2} \mathrm{O}_{3}$ catalysts. 


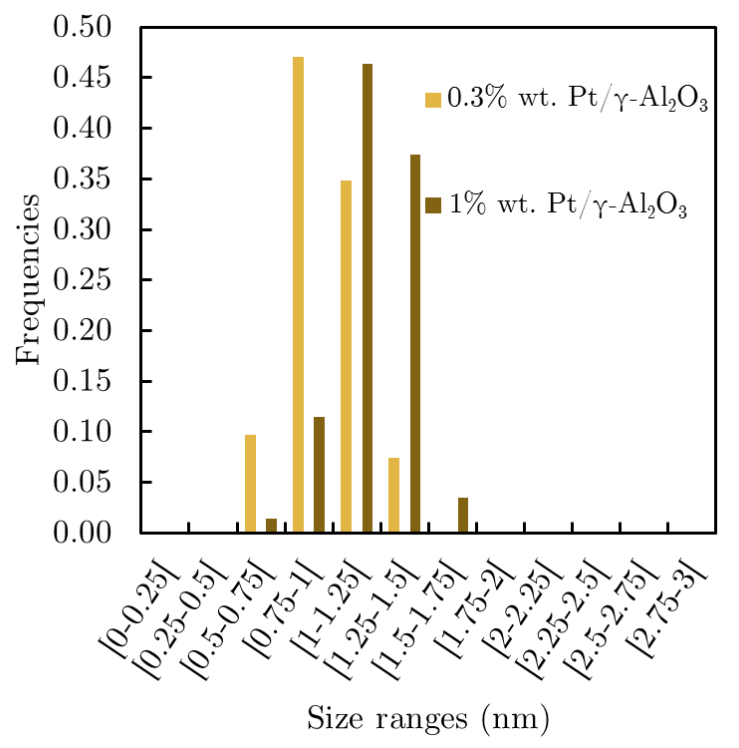

Figure 2: Particle size distribution of the fresh 0.3 and $1 \mathrm{wt} \% \mathrm{Pt} / \gamma-\mathrm{Al}_{2} \mathrm{O}_{3}$ catalysts after dechlorination (resp. 143 and 289 items probed).

\section{2. $\mathrm{O}_{2}$-TPD experiments}

For the $1 \mathrm{wt} \% \mathrm{Pt} / \mathrm{Al}_{2} \mathrm{O}_{3}$ catalyst, $\mathrm{O}_{2}$ desorption is detected mainly at $504^{\circ} \mathrm{C}$ and $757^{\circ} \mathrm{C}$ (Figure

3). The peaks deconvolution with a Gaussian fit allows to put into evidence a shoulder at $835^{\circ} \mathrm{C}$ (Supporting Information S5). The main peak is shifted to $710^{\circ} \mathrm{C}$ on the $0.3 \mathrm{wt} \% \mathrm{Pt} / \mathrm{Al}_{2} \mathrm{O}_{3}$ catalyst while shoulders are detected at $515^{\circ} \mathrm{C}$ and $931^{\circ} \mathrm{C}$. In quantitative terms, the system with the lowest Pt content $(0.3 \mathrm{wt} \% \mathrm{Pt})$ leads to an enhancement of the highest temperature peak and a decrease of the lower temperature peak as compared to the system with the highest Pt content $(1 \mathrm{wt} \%)$. 


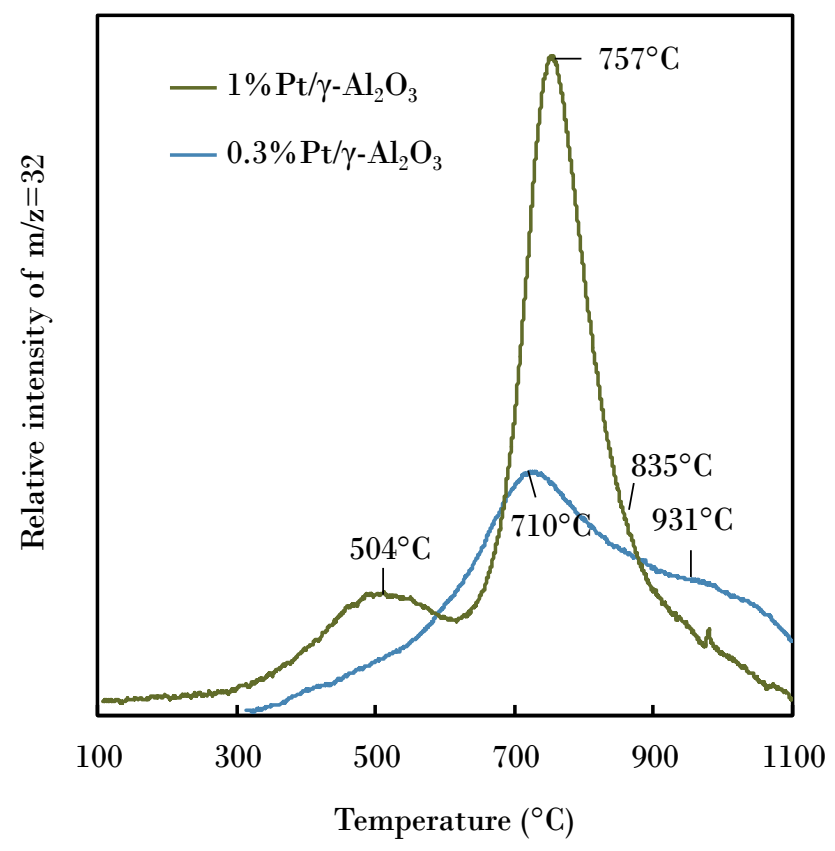

Figure 3 : Relative intensity of oxygen $(\mathrm{m} / \mathrm{z}=32)$ during the Temperature-Programmed Desorption with the 0.3 wt $\%$ and $1 \mathrm{wt} \% \mathrm{Pt} / \gamma-\mathrm{Al}_{2} \mathrm{O}_{3}$ catalysts.

Parker et al. report the TPD of $\mathrm{O}_{2}$ on $\mathrm{Pt}(111)$ with different initial oxygen coverages. ${ }^{93}$ They show that for coverages lower than $0.2 \mathrm{ML}$, only one peak appears around $460-540^{\circ} \mathrm{C}$. A second peak at $400^{\circ} \mathrm{C}$ is noticed for higher oxygen coverages and a third one lies at $120^{\circ} \mathrm{C}$ for initial oxygen coverages above $0.5 \mathrm{ML}$. No desorption is reported above $680^{\circ} \mathrm{C}$. For stepped surfaces ${ }^{94} \mathrm{a}$ similar pattern is observed with peaks lying between $300^{\circ} \mathrm{C}$ and $600^{\circ} \mathrm{C}$, with two peaks close to $400^{\circ} \mathrm{C}$ and $500^{\circ} \mathrm{C}$. Our results show that desorption of oxygen on highly dispersed platinum particles supported on alumina occurs on a completely different range of temperature. This suggests that the platinum dispersion has a huge impact on oxygen interaction with platinum, thus on $\mathrm{O}_{2}$ desorption profile. The shift of $\mathrm{O}_{2}$ desorption peaks towards high temperature can be associated with stronger interactions between oxygen and platinum atoms in the case of highly 
dispersed platinum particles on alumina. In previous reports dealing with more or less dispersed $\mathrm{Pt} / \mathrm{Al}_{2} \mathrm{O}_{3}$ catalysts, the main desorption peaks appeared below $500^{\circ} \mathrm{C}$, but temperatures higher than $700^{\circ} \mathrm{C}$ were generally not sampled. ${ }^{34,95-96}$

\section{Ab initio simulation of oxygen adsorption reactions}

Ab initio electronic structures calculations were undertaken on $\mathrm{Pt}_{13} \mathrm{O}_{\mathrm{n}} / \gamma-\mathrm{Al}_{2} \mathrm{O}_{3}$ model to simulate the behavior of highly dispersed platinum. Pt(111) was also considered to compare with the behavior of large particles or ideal metal surfaces. It also provides a good reference case (Supporting Information S6).

\subsection{Adsorption of atomic oxygen}

The 13-platinum atoms particle model is supported on a (100) gamma alumina surface model. ${ }^{53}$ The particle is composed of two layers of platinum atoms, among which 12 atoms out of 13 are $a$ priori accessible to external molecules. This corresponds to a theoretical dispersion of 0.92 . This small particle implies a non-regular surface on which no typical extended surface emerges.

Due to the absence of symmetry, each platinum atom and thus each site has a unique behavior. First, we simulated about 60 potential adsorption sites for oxygen (top, bridge and hollow sites) by geometry optimization. Among the simulated configurations, some of them evolved into more stable ones. The adsorption energies obtained are summarized in Figure 4. Their average, by adsorption mode (as detailed below) is given in Table 1. Some of these structures are shown in Figure 5. 


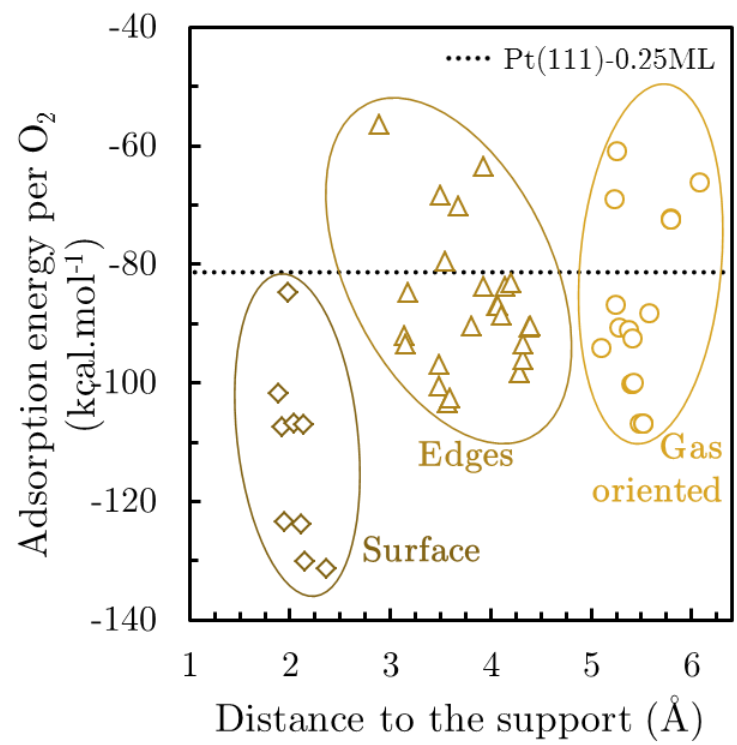

Figure 4 : Adsorption energies per $\mathrm{O}_{2}$ for a single $\mathrm{O}$ atom on the supported $\mathrm{Pt}_{13}$ cluster, as a function of the distance to the support compared to $\operatorname{Pt}(111)-0.25 \mathrm{ML}$. The distance to the support corresponds to the difference between oxygen and mean aluminum of the first alumina layer $\mathrm{z}$ coordinates.

From Figure 4, three groups emerge according to their distance from the support. A first group, close to alumina (from 1 to $2.5 \AA$ ) is composed of the more stabilizing sites for atomic oxygen. This group corresponds to non-expected adsorption sites that involve the alumina support. Figure $5 \mathrm{~d}$ shows one of these structures, with the oxygen bonded to one platinum and one aluminum atom. Such site is hereafter named bimetallic bridge. The bimetallic hollow site (Figure 5e) is composed of two platinum atoms and one aluminum. These peculiar sites which involve the

Table 1: Average adsorption energy per $\mathrm{O}_{2}$, at low oxygen coverage. 


\begin{tabular}{|c|c|c|}
\hline \multirow{2}{*}{ Adsorption mode } & Adsorption mode & $\mathrm{E}_{\text {adsorption }}\left(\mathrm{kcal}^{-\mathrm{mol}^{-1}}\right)$ \\
\hline \multirow{4}{*}{$\mathrm{Pt}_{13} \mathrm{O}-$ this work } & top & -89.8 \\
\cline { 2 - 3 } & bridge & -83.9 \\
\cline { 2 - 3 } & hollow & -87.7 \\
\cline { 2 - 3 } & bimetallic bridge $(\mathrm{Al}, \mathrm{Pt})$ & -108.1 \\
\cline { 2 - 3 } & bimetallic hollow & -122.8 \\
\hline $\mathrm{Pt}(111)-$ this work & (Al,2Pt) & -81.3 \\
\hline $\mathrm{Pt}(111)^{20}$ & $0.25 \mathrm{ML}$ & -47.5 \\
\hline $\mathrm{Pt}(111)^{21}$ & $0.25 \mathrm{ML}$ fcc hollow & -69.6 \\
\hline $\mathrm{Pt}(321)^{30}$ & $0.25 \mathrm{ML}$ fcc hollow & -67.2 \\
\hline & near-edge fcc hollow & $-75.2(\mathrm{x}=1)$ \\
& Top & $-79.4(\mathrm{x}=2)$ \\
\hline & Top, bridge & $-79.8(\mathrm{x}=3)$ \\
\hline Non supported $\mathrm{Pt}_{\mathrm{x}} \mathrm{O}_{\mathrm{x}}{ }^{49}$ & Bridge & $-88.4(\mathrm{x}=4)$ \\
& Bridge & $-86.8(\mathrm{x}=5)$ \\
& Bridge & $-112.6(\mathrm{x}=10)$ \\
\hline Non supported $\mathrm{Pt}_{13}{ }^{48}$ & Top, bridge & -60.9 \\
\hline
\end{tabular}

2 The second group of sites, exhibiting a distance to the surface between $2.5 \AA$ and $4.4 \AA$ involves 3 two layers of platinum. They correspond to oxygen atoms adsorbed on the edges of the cluster. 4 The adsorption energies are dispersed (from -60 to $-100 \mathrm{kcal}_{\mathrm{mol}}{ }^{-1}$ ) but they are significantly less 5 negative in average as compared to the first group. The third group includes the farthest sites, i.e. 6 located on the top of the particle (gap with the second group: $0.75 \AA$ ). The oxygen atoms are 7 oriented to the gas phase (Figure 5a to 5c). The adsorption energy range does not differ 8 significantly from the second group. These data illustrate the significant promoting effect of the 9 support. 

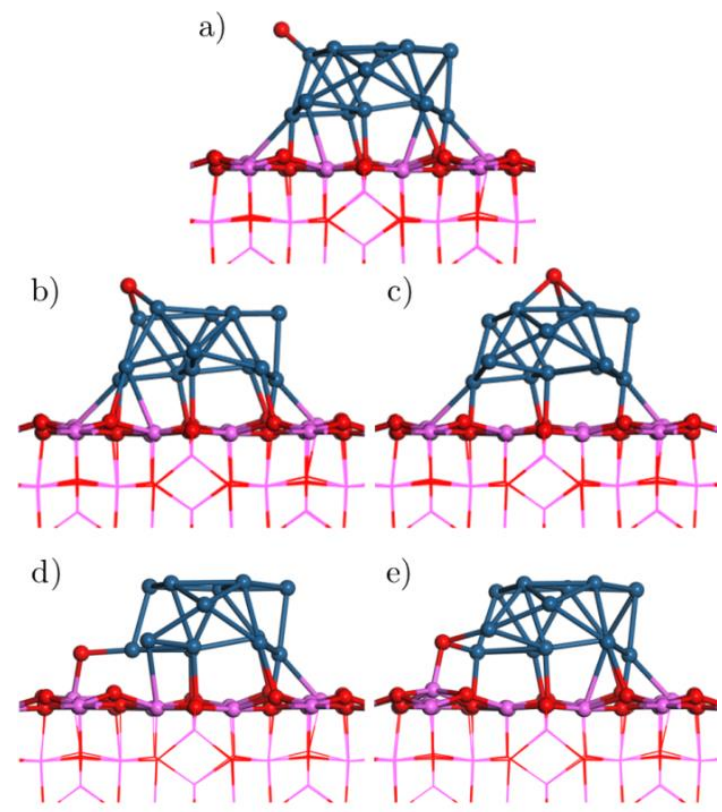

Figure 5 : Illustration of top (a), bridge (b) and hollow (c) typical sites with bimetallic (Al, Pt) bridge (d) and hollow (Al, Pt, Pt) sites (e). Platinum atoms are in blue, alumina in pink and oxygen in red.

The adsorption energies (in absolute value) at low coverage on $\operatorname{Pt}(111)$ are much lower than most of the $\mathrm{Pt}_{13} \mathrm{O}$ adsorption energies (Table 1 and Supporting Information S6). However the $\operatorname{Pt}(111)$ system with $0.25 \mathrm{ML}$ of oxygen exhibits a similar adsorption energy $\left(-81.3 \mathrm{kcal}^{\mathrm{mol}} \mathrm{m}^{-1}\right)$ with respect to the particle traditional sites (edges and gas oriented). This tends to indicate that at low oxygen coverage the main factors determining reactivity are the nature of the support and its interaction with platinum. Mihai et al. ${ }^{96}$ experimentally quantified the heat of adsorption of $\mathrm{O}_{2}$ on poorly dispersed $\mathrm{Pt} / \mathrm{Al}_{2} \mathrm{O}_{3}$ catalysts (dispersion: 0.12 ), and obtained values close to $-70 \mathrm{kcal} / \mathrm{mol}$, close to single crystal experiments, ${ }^{97}$ showing that the support effects becomes substantial only for highly dispersed catalysts, such as the one considered in the present work.

Also adsorption energies on the supported cluster are of the same order of magnitude as nonsupported nano-oxides $\left(\mathrm{n}_{\mathrm{Pt}}<13\right)$ studied by Schneider et al. ${ }^{49}$ At this scale, the bridge adsorption 
mode is clearly preferred. The case of non-supported $\mathrm{Pt}_{13}$ as investigated by Zhang et $\mathrm{al}^{48}$ is the exception with two top oxygen atoms, with an adsorption energy close to $\operatorname{Pt}(111)$ one. This supports the idea that alumina support favors oxygen adsorption.

\subsection{Evolution of adsorption properties with $O$ coverage and cluster structuration}

Higher oxygen coverages were then investigated. Molecular dynamics was used systematically from $\mathrm{Pt}_{13} \mathrm{O}_{2}$ to $\mathrm{Pt}_{13} \mathrm{O}_{32}$ to identify stable configurations (Supporting Information S1). The energetic feature of the most stable systems found is shown in Figure 6. The structure of the systems exhibiting a significant stability domain is depicted in Figure 7, whereas all the discussed structures are reported in Supporting Information S7.

For all coverages, the bridge adsorption mode is preferred for oxygen on the particle. In the case of bimetallic sites, the bridge mode is still represented but the bimetallic hollow site ( 2 platinum, one aluminum) dominates. From two oxygen atoms adsorbed, the cluster gradually reconstructs. Two-layers-like structures (noticed TL) are the most stable up to 12 oxygen atoms, deviating however strongly from the initial one (without oxygen). Therefore the 13 platinum atoms become all accessible for $\mathrm{n}>10$, the single initially occluded atom being displaced in such a way by oxygen that it becomes accessible. At higher oxygen coverages, the particles from $\mathrm{Pt}_{13} \mathrm{O}_{18}$ to $\mathrm{Pt}_{13} \mathrm{O}_{26}$ exhibit a fully reconstructed hemispheric shape, referred to hereafter as $\mathrm{HM}$. Within this structure, platinum atoms are tetra- and pentavalent. The oxygen atoms are interspersed between the platinum ones. This increases the volume of the cluster up to $290 \%$ (volume of the platinum polyedra of $84.1 \AA^{3}$ for $\mathrm{Pt}_{13}$ to $201 \AA^{3}$ for $\mathrm{Pt}_{13} \mathrm{O}_{24}$ ). The transition between these two cluster shapes (two-layers and hemispheric) appears for intermediate coverages between 14 and 16 oxygen atoms, with a smooth energetic transition (Figure 6). 


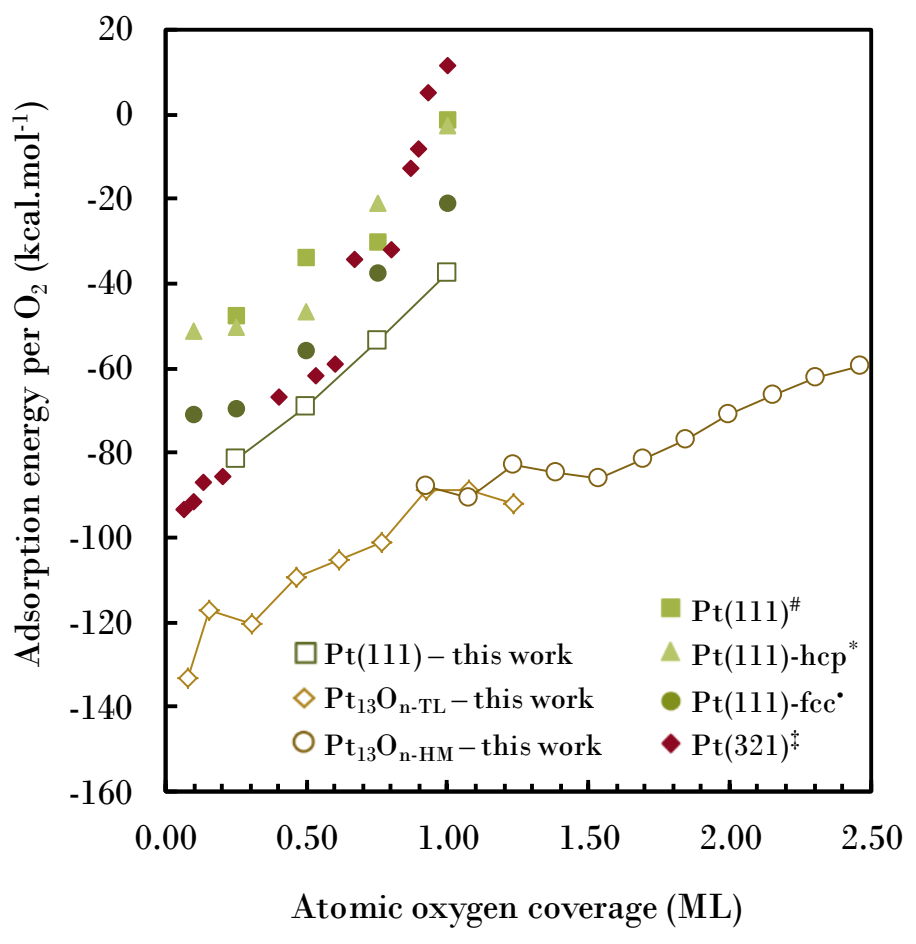

Figure 6 : Mean adsorption energies of $\mathrm{O}_{2}$ according to the oxygen coverage for supported $\mathrm{Pt}_{13} \mathrm{O}_{\mathrm{n}}$ structures and $\mathrm{Pt}(111) .{ }^{\#}$ Légaré, ${ }^{20}{ }^{*}$ Pang et al., ${ }^{21}$ Schneider and coworkers. ${ }^{30}$ For $\mathrm{Pt}_{13} \mathrm{O}_{\mathrm{n}}$ structures, the monolayer is calculated as the number of oxygen atoms divided by 13,13 being the number of accessible platinum atoms. Therefore $\mathrm{Pt}_{13} \mathrm{O}_{26}$ is considered as a $2 \mathrm{ML}$ structure.

Finally, the structures at very high coverage, starting from $\mathrm{Pt}_{13} \mathrm{O}_{26}$, show the disintegration of the hemispheric shape by adsorption of additional oxygen atoms in top mode. This comes along with the segregation of a few platinum atoms. Non-dissociated $\mathrm{O}_{2}$ molecules can also be distinguished at high coverages. Although a reconstruction was also observed upon exposure to hydrogen, ${ }^{41,63}$ the latter is very different in nature with respect to the one calculated here for oxygen: the bilayer cluster transforms into a cuboctahedron from 20 hydrogen atoms per cluster, with loss of covalent bonding with the support. 
The evolution of the average adsorption energy according to oxygen coverage (Figure 6) 2 decreases (in absolute value) continuously in a quasi-linear way. These values contrast significantly with the ones reported with extended surfaces as $\operatorname{Pt}(111)^{20-21}$ and $\operatorname{Pt}(321) .^{30}$ The cluster shows a huge capacity of stabilizing oxygen atoms on it.

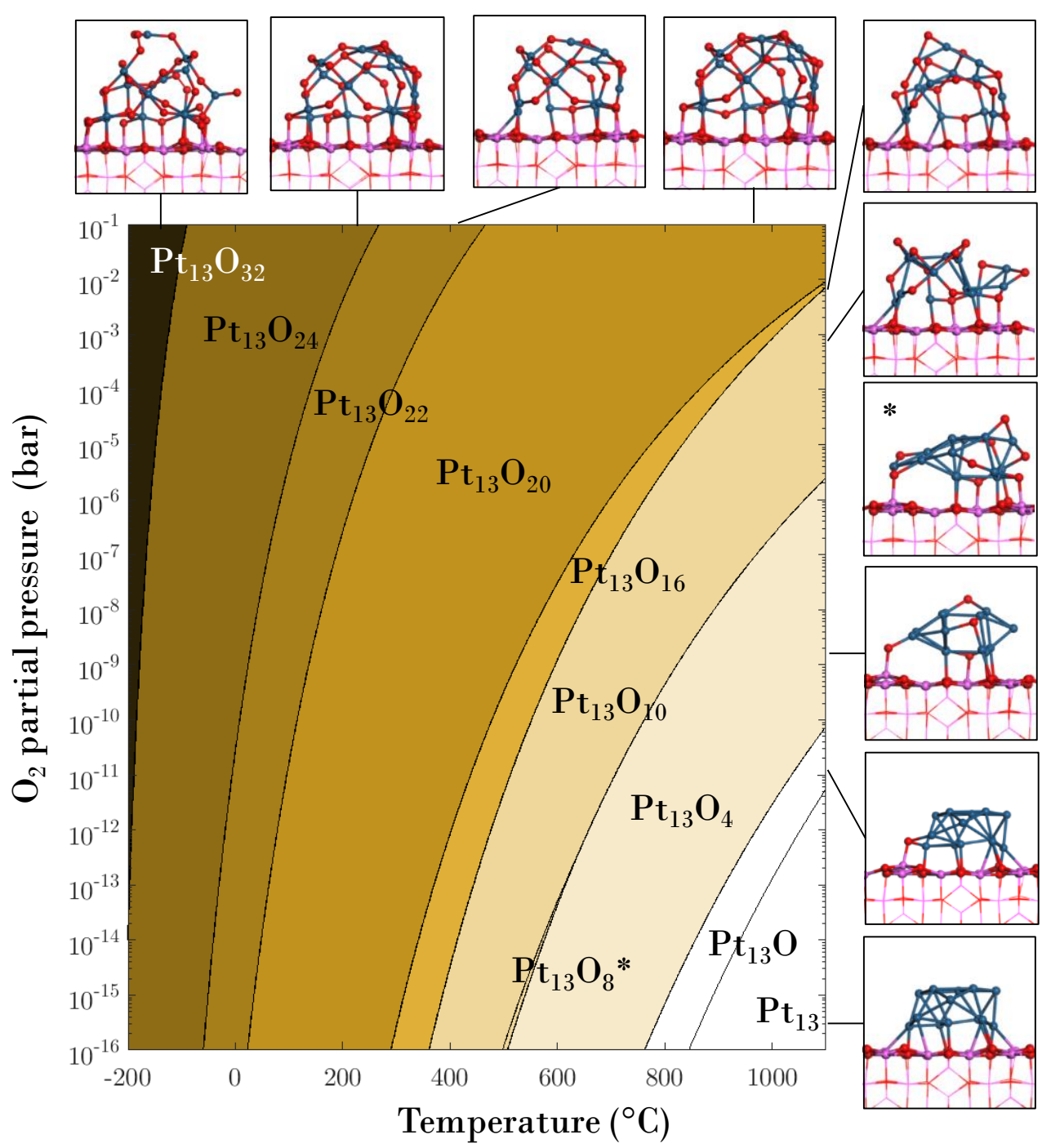

Figure 7 : Phase diagram for supported $\mathrm{Pt}_{13} \mathrm{O}_{\mathrm{n}}$ according to temperature and partial pressure of oxygen. The structures of the systems exhibiting a significant stability domain are also depicted (side views). 
A $\left(\mathrm{P}_{\mathrm{O} 2}, \mathrm{~T}\right)$ phase diagram was built thanks to entropy and enthalpy obtained with ab initio structures (Figure 7). Contrary to the case of Pt(111) (Supporting Information S6), the diagram for supported $\mathrm{Pt}_{13}$ only shows a very small stability domain for zero oxygen coverage. This means that the cluster is always oxidized for realistic oxygen partial pressures, in the absence of reducing agent. The diagram is mainly occupied by the high coverage hemispheric structures, having 16 to 24 oxygen atoms. This is compatible with the experimental observation of poisoning of platinum by oxygen at low dispersion. ${ }^{98}$

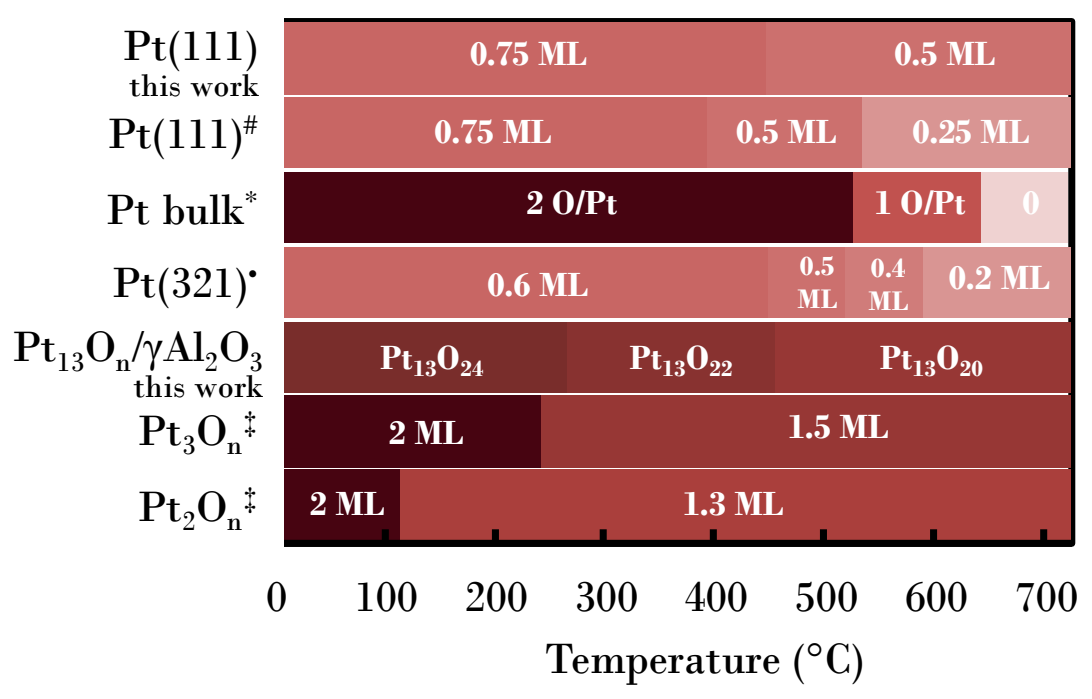

Figure 8 : Comparison of platinum-oxygen phase diagrams at $\mathrm{P}_{\mathrm{O} 2}=0.1$ bar according to the nature of the surface. ${ }^{\#}$ Légaré, ${ }^{20}$ *Phase diagram of the bulk platinum in presence of only $\mathrm{O}_{2}$ by HSC Chemistry data, 'Schneider and co-workers, ${ }^{30}$ Schneider and coworkers. ${ }^{49-50}$

Figure 8 summarizes the phase diagrams reported in the literature for a common partial pressure of $\mathrm{O}_{2}$ of 0.1 bar. The capacity of the 13-platinum cluster to hold oxygen is of the same order of magnitude as the non-supported $\mathrm{Pt}_{2}$ and $\mathrm{Pt}_{3}$ particles studied by $\mathrm{Xu}$ and coworkers. ${ }^{49-50}$ This is much higher than the extended surfaces capacity in this condition, but closer to the bulk capacity. 
The high dispersion, the ductility of the platinum clusters and the energetics of oxygen adsorption 2 sites are directly related to the capacity of holding such a quantity of oxygen, even at high 3 temperature. This gives an atomistic picture of the origin of the differences between large and small platinum particles, for oxygen adsorption and reactions. ${ }^{18,36,98}$ Moreover, the stoichiometry of the supported cluster is close to $\mathrm{PtO}_{2}$ in these pressure conditions, over a large range of temperature.

The platinum/alumina interaction energy is globally strengthening as the oxygen coverage increases (Figure 9a). The opposite trend was noticed on $\mathrm{Pt}_{13} \mathrm{H}_{\mathrm{n}}$ structures, ${ }^{63}$ with an unhooking of the cluster from the support. The impact of the metal/support interaction on the related bond length is not strong (Figure 9b).
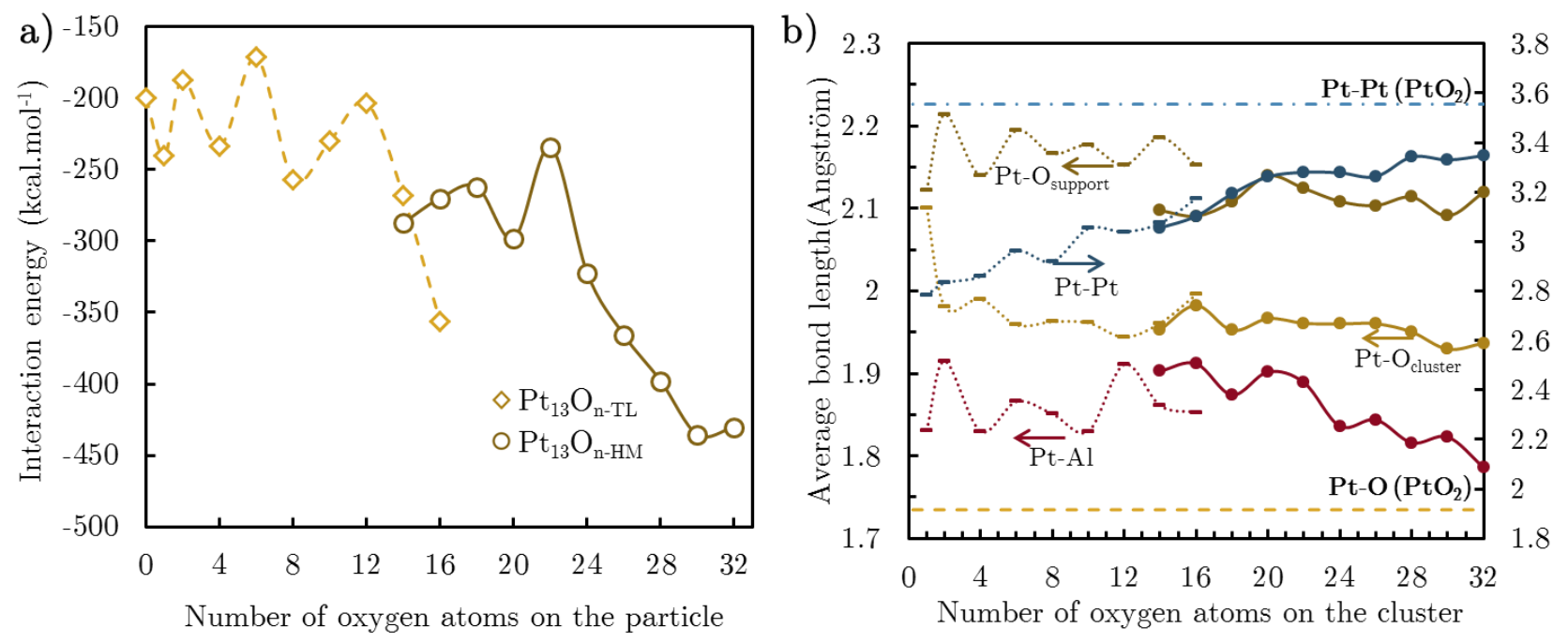

Figure 9 : (a) Interaction energy between the alumina support and the oxidized platinum clusters. (b) Average Pt-Pt, Pt- $\mathrm{O}_{\text {support }}$ and $\mathrm{Pt}-\mathrm{O}_{\text {cluster }}$ bond lengths, and minimum Pt-Al length as a function of oxygen coverage. The maximal bond lengths were set to $3.8 \AA$ for Pt-Pt and $2.5 \AA$ for other bonds. Dotted lines corresponds to the two-layers structures whereas plain lines are hemispheric structures data. 
Indeed, the average lengths of Pt-Al and Pt- $\mathrm{O}_{\text {support }}$ bonds do not vary by more than $5 \%$. The 2 single trends that can be seen is the shortening of the Pt-O $\mathrm{O}_{\text {support }}$ bonds from the bi-planar to the hemispheric structures, in line with the strengthening of the interaction. Moreover a substitution of Pt-Al by Al-O $\mathrm{O}_{\text {cluster }}$ bonds occurs with increasing oxygen coverage (Supporting Information S7). Likely, the strongest cluster/support interaction comes from those additional Al- $\mathrm{O}_{\text {cluster }}$ bonds. The rise. The $\mathrm{Pt}_{13} \mathrm{O}_{14}$ and $\mathrm{Pt}_{13} \mathrm{O}_{16}$ structures that coexists in the two structure types show that the Pt-Pt bonds are slightly shorter for the hemispheric cluster shape than for two-layers structure.

To further investigate the impact of oxygen coverage on charge transfer, the Bader partial charges were computed for platinum and oxygen on the cluster (Figure 10). The oxygen charge remains almost constant with oxygen coverage (between -1 and -0.5 ), close to the oxygen Bader charge of $\mathrm{PtO}_{2}$ oxide. However the charge of platinum is increasing almost linearly with coverage, starting from a $\mathrm{Pt}^{0}$ to a 1.2 electron-depleted platinum for very high oxygen coverage, quite close to a kind of $\mathrm{PtO}_{2}$ charge. The smooth transition noticeable from two-layers to hemispheric structures emphasizes the blurred energetic transition discussed previously, showing also that Bader charges are mainly dominated by the stoichiometry of the supported oxide, more than by the morphology. Note that the total charge of the cluster (platinum plus oxygen) remains very close to zero, showing a very weak charge transfer with the support for particles holding oxygen, contrary to what was reported in the presence of hydrogen as adsorbate. ${ }^{63}$ 


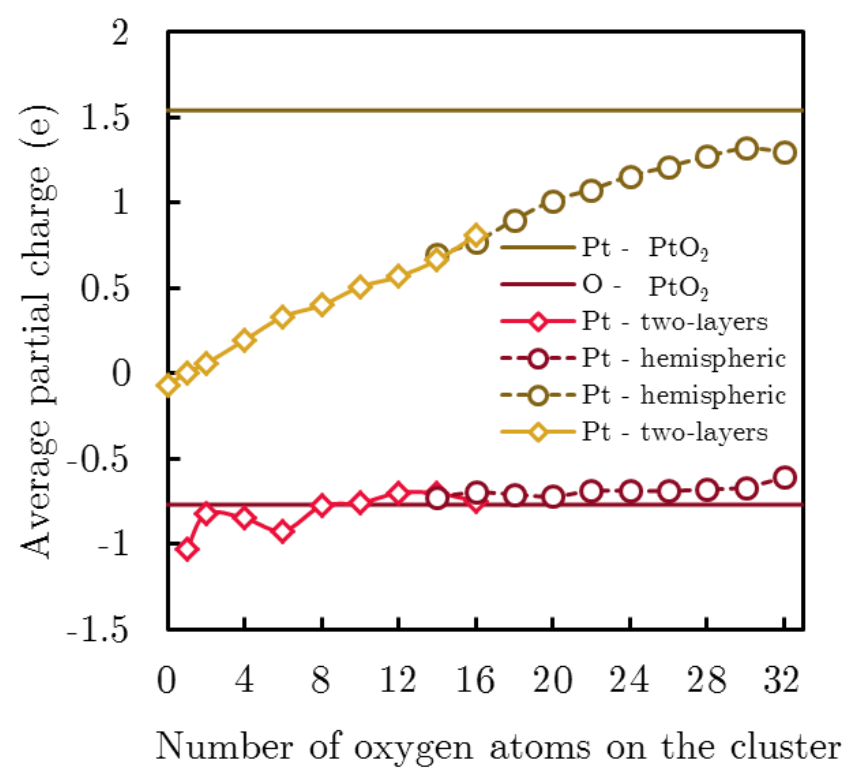

Figure 10 : Mean Bader charge per Pt (blue) and cluster O (red) atoms. The cross-shaped dots represent the two-layers structures while the full dots stand for hemispheric structures.

\subsection{Activation energy for the dissociation of $\mathrm{O}_{2}$}

Potential energy surfaces and transition states for $\mathrm{O}_{2}$ dissociation were determined on $\mathrm{Pt}_{13} / \gamma$ $\mathrm{Al}_{2} \mathrm{O}_{3}$ model, in comparison with $\mathrm{Pt}(111)$. For the supported cluster, three coverages were investigated: (1) the dissociation of $\mathrm{O}_{2}$ on a reduced particle (from 0 to 2 oxygen atoms per cluster), (2) with an intermediate coverage on a two-layers cluster structure (from 8 to 10 oxygen atoms per cluster) and (3) on a high oxygen coverage cluster with an hemispheric shape (from 22 to 24 oxygen atoms per cluster). For Pt(111), two energetic pathways were investigated: the dissociation of $\mathrm{O}_{2}$ on a reduced surface and another one with an initial 0.5 ML atomic oxygen coverage. On the later structure, the dissociation leads to a $1 \mathrm{ML}$ oxygen coverage. In all cases, this evaluation was performed using the most stable final state. The energy paths are summarized in Figure 11, key-structures (including transition structures) being shown in Supporting 
Information S8. The later corresponds to the O-O bond elongation. Adsorption of a non2 dissociated $\mathrm{O}_{2}$ is energetically favored, more strongly on the clusters than on $\operatorname{Pt}(111)$. Notably, on $\mathrm{Pt}(111)$, the molecular adsorption of $\mathrm{O}_{2}$ is more favorable on the reduced surface, whereas the reverse trend is observed for the cluster, with more negative energies in the case of the oxidized cluster.

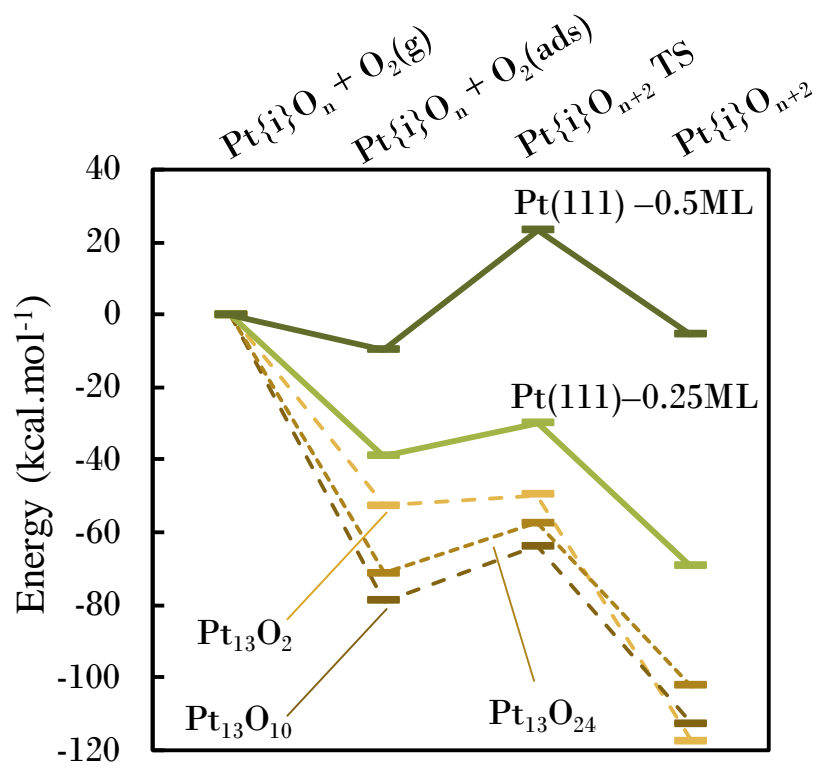

Figure 11 : Dissociation barriers from initial state $\mathrm{Pt}_{13} \mathrm{O}_{\mathrm{n}}$ to $\mathrm{Pt}_{13} \mathrm{O}_{\mathrm{n}+2}$, and $\mathrm{Pt}(111) \mathrm{O}_{\mathrm{n}}$ to $\mathrm{Pt}(111) \mathrm{O}_{\mathrm{n}+2}$. The energies are displayed relatively to each initial state energy.

The dissociation barriers from adsorbed $\mathrm{O}_{2}$ (forward and backward) are given in Table 2. Fu et surface of $\operatorname{Pt}(111) .{ }^{56}$ A $8.3 \mathrm{kcal}^{\mathrm{mol}}{ }^{-1}$ barrier is calculated for the low coverage dissociation on Pt(111). It reaches $32.5 \mathrm{kcal} . \mathrm{mol}^{-1}$ for the medium coverage. Consequently, the atomic oxygen coverage has a significant inhibiting effect on $\mathrm{O}_{2}$ dissociation for $\mathrm{Pt}(111)$. For the supported $\mathrm{Pt}_{13}$ cluster, a $3 \mathrm{kcal}^{\mathrm{mol}} \mathrm{m}^{-1}$ barrier for the reduced particle is obtained while the one with a medium 
coverage is about $15 \mathrm{kcal}_{\mathrm{mol}}{ }^{-1}$, despite the same two-layers structure. On the contrary, no 2 significant influence of the cluster structuration (HM versus TL) is noticed as the activation energy found for $\mathrm{Pt}_{13} \mathrm{O}_{24}$ formation is almost equivalent to that of $\mathrm{Pt}_{13} \mathrm{O}_{10}$. Note that $\mathrm{Zhang}$ and coworkers ${ }^{48}$ found an activation energy of $10 \mathrm{kcal}^{\mathrm{mol}} \mathrm{m}^{-1}$ on a non-supported $\mathrm{Pt}_{13}$ reduced particle, within the interval we find here.

Table 2: Dissociation and association barriers for $\mathrm{O}_{2}$ dissociation on $\mathrm{Pt}(111)$ and $\mathrm{Pt}_{13} \mathrm{O}_{\mathrm{n}}$ cluster

\begin{tabular}{|c|c|c|}
\hline Reaction & $\begin{array}{c}\text { Dissociation barrier } \\
\left(\mathrm{kcal}^{-m_{0}}{ }^{-1}\right)\end{array}$ & $\begin{array}{c}\text { Association barrier } \\
\left(\mathrm{kcal}^{-1} \mathrm{~mol}^{-1}\right)\end{array}$ \\
\hline $\mathrm{Pt}(111)+\mathrm{O}_{2}(\mathrm{~g}) \rightarrow \mathrm{Pt}(111)-0.25 \mathrm{ML}$ & 8.3 & 67.7 \\
\hline $\mathrm{Pt}(111)-0.25 \mathrm{ML}+\mathrm{O}_{2}(\mathrm{~g}) \rightarrow \mathrm{Pt}(111)-0.5 \mathrm{ML}$ & 32.5 & 48.9 \\
\hline $\mathrm{Pt}_{13}+\mathrm{O}_{2}(\mathrm{~g}) \rightarrow \mathrm{Pt}_{13} \mathrm{O}_{2}$ & 3.0 & 47.8 \\
\hline $\mathrm{Pt}_{13} \mathrm{O}_{8}+\mathrm{O}_{2}(\mathrm{~g}) \rightarrow \mathrm{Pt}_{13} \mathrm{O}_{10}$ & 15.1 & 39.2 \\
\hline $\mathrm{Pt}_{13} \mathrm{O}_{22}+\mathrm{O}_{2}(\mathrm{~g}) \rightarrow \mathrm{Pt}_{13} \mathrm{O}_{24}$ & 13.8 & 45.0 \\
\hline \multicolumn{2}{|l}{} \\
\hline
\end{tabular}

To conclude, the ab initio investigations of supported $\mathrm{Pt}_{13} \mathrm{O}_{\mathrm{n}}$ clusters reveals a very strong affinity of the catalytic system for oxygen, leading to highly oxidized stoichiometry, the metal/support interaction is strengthened upon oxidation thanks to Platinum-Oxygen-Aluminum briges. A reconstruction takes place, from a biplanar-like morphology at low coverage, to hemispherical shapes at high coverage. Dissociation barriers of $\mathrm{O}_{2}$ were also determined and significantly depend on the oxygen coverage. It is now worth analyzing the macroscopic consequences of such microscopic features, which is done thanks to multi-scale kinetic modeling. 


\title{
5. Kinetic modeling of $\mathrm{O}_{2}$-TPD
}

\begin{abstract}
Detailed kinetic models were developed to deduce the expected TPD profile from $a b$ initio
\end{abstract} calculations (Supporting Information S9), together with the definition of the surface species present throughout the TPD. The kinetic model analysis is performed on several key parameters in order to evaluate its ability to simulate the TPD. Prior $a b$ initio calculations emphasize on close energy structures for specific oxygen coverages. The impact of the scheme structuration on the $\mathrm{O}_{2}$ release has been benchmarked. This allows to evaluate the scheme complexity level towards experimental data. Considering a scheme that takes into account all the structures, sensitivity analysis and reaction path analyses have been performed. Therefore both key structures and reactions are identified.

\subsection{Impact of the dispersion on $\mathrm{O}_{2}$-TPD}

The most stable structures determined by ab initio calculations for each oxygen coverage were used to build the present kinetic mechanism. To represent the complex transition between the twolayers (TL) and hemispheric (HM) structures, two structures were considered for $\mathrm{Pt}_{13} \mathrm{O}_{14}$ and $\mathrm{Pt}_{13} \mathrm{O}_{16}$ with their own kinetic parameters. To correctly depict this transition, two reversible surface reactions were implemented to connect one structure to the other. The activation energies come from ab initio data, the pre-exponential factors were set to $10^{11} \mathrm{~s}^{-1}$ as recommended for nonrotating and non-mobile adsorbate by Dumesic et al. ${ }^{99}$

An important parameter likely affected by Pt dispersion is the sticking coefficient (equation 6). Ertl et al. investigated it on $\operatorname{Pt}(111)$ in vacuum conditions. ${ }^{22}$ They found that it depends on the collision angle with the surface, the oxygen coverage and the temperature, and is of the order of 
$1 \quad 10^{-2}$. Therefore, several coefficients were attempted in this work for the $\mathrm{Pt}_{13}$ mechanism, starting 2 from a trial value of $10^{-2}$.
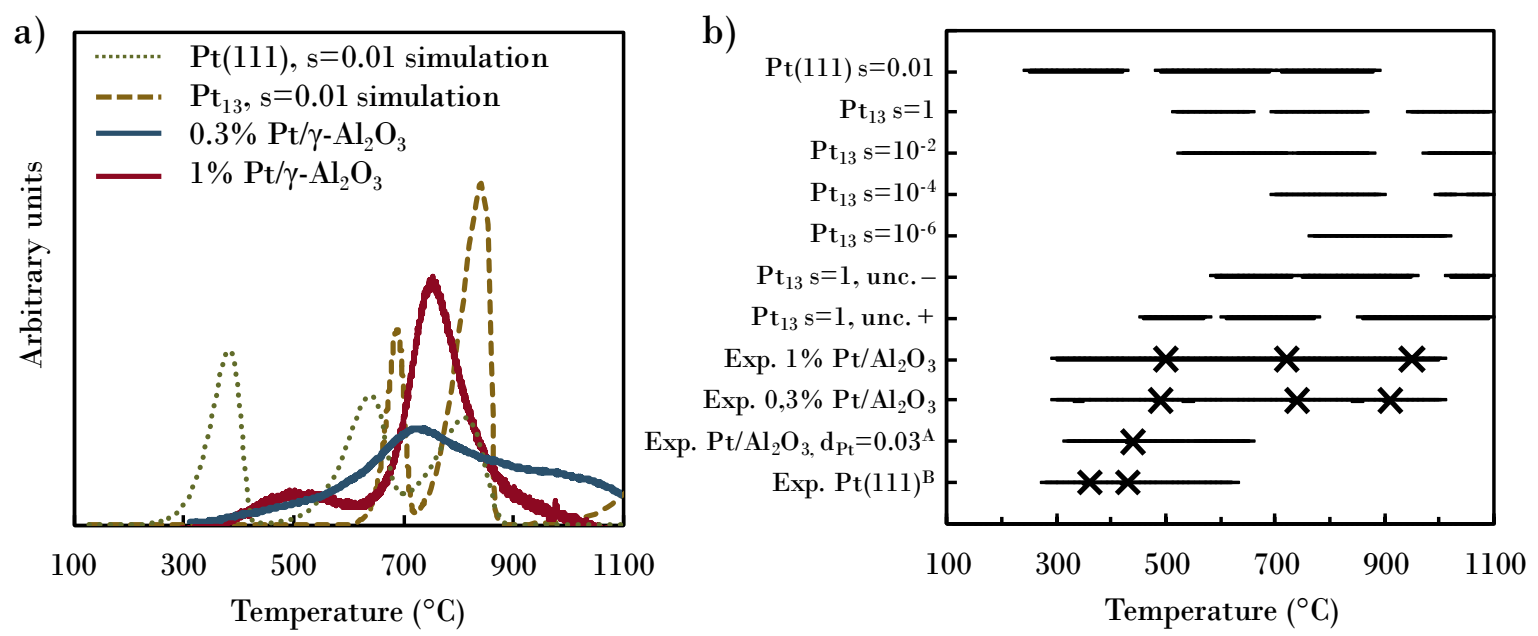

Figure 12: (a) Predicted $\mathrm{O}_{2}$ concentration profile during $\mathrm{O}_{2}-\mathrm{TPD}$ with $\mathrm{Pt}(111)$ and $\mathrm{Pt}_{13}$, with $\mathrm{TPD}$ experiments on highly-dispersed $\mathrm{Pt} / \gamma-\mathrm{Al}_{2} \mathrm{O}_{3}$. (b) Impact of sticking coefficient and of a typical error $( \pm 3.6$ kcal.mol ${ }^{-1}$ for enthalpies and $\pm 3.6 \mathrm{cal}^{\mathrm{mol}} \mathrm{m}^{-1} \cdot \mathrm{K}^{-1}$ for entropies, see text) on $\mathrm{Pt}_{13}$ kinetic model with a $5^{\circ} \mathrm{C} /$ min temperature ramp and starting with the $\mathrm{Pt}_{13} \mathrm{O}_{20}$ structure. The $\mathrm{O}_{2}$-TPD experiments of ${ }^{\mathrm{A}}$ Olsson et al. ${ }^{95}$ and ${ }^{\mathrm{B}}$ Parker et al. ${ }^{93}$ are also reported. The lines represent the range of occurrence of $\mathrm{O}_{2}$ release and the crosses the associated rate-of-desorption maxima.

Figure 12 shows the simulations of the $\mathrm{O}_{2}$-TPD experiment with $\mathrm{Pt}(111)$ and $\mathrm{Pt}_{13}$ kinetic models with a sticking coefficient of $10^{-2}$ for all reactions. The $\mathrm{Pt}_{13}$ simulation exhibits two successive desorption peaks at $686^{\circ} \mathrm{C}$ and $839^{\circ} \mathrm{C}$ corresponding to the transition from $\mathrm{Pt}_{13} \mathrm{O}_{20}$ to $\mathrm{Pt}_{13} \mathrm{O}_{16-\mathrm{TL}}$ and then to $\mathrm{Pt}_{13} \mathrm{O}_{4}$ respectively. These peaks lie in the temperature ranges of the main experimental $\mathrm{TPD}$ peak, above $700^{\circ} \mathrm{C}$. In the case of the $\operatorname{Pt}(111)$ simulation, three peaks are obtained (at $384^{\circ} \mathrm{C}, 639^{\circ} \mathrm{C}$ and $814^{\circ} \mathrm{C}$ for $\mathrm{s}=10^{-2}$, corresponding to $0.75 \mathrm{ML} \rightarrow 0.50 \mathrm{ML} \rightarrow 0.25 \mathrm{ML}$

$\rightarrow 0 \mathrm{ML}$ respectively). The desorption is here centered around $600^{\circ} \mathrm{C}$. 
Experimental TPD of Olsson et al. ${ }^{95}$ (poorly dispersed supported catalysts) and Parker et al. ${ }^{93}$ $(\operatorname{Pt}(111))$ show respectively one and three peaks in the same temperature range from $300^{\circ} \mathrm{C}$ to $600^{\circ} \mathrm{C}$. The temperature ramp applied in their studies are quite different $\left(40^{\circ} \mathrm{C} / \mathrm{min}\right.$ and $8^{\circ} \mathrm{C} / \mathrm{s}$ respectively) and may impact $\mathrm{O}_{2}$-TPD shape. In contrast, the $\mathrm{O}_{2}$ adsorption kinetic parameters of Deutschmann ${ }^{100}$ (version of nov. 1995 with duplicated adsorption reaction) were implemented in our own kinetic model, which leads to a broad signal from $100^{\circ} \mathrm{C}$ to $1100^{\circ} \mathrm{C}$ with a simulated ramp of $5^{\circ} \mathrm{C} / \mathrm{min}$

The sticking coefficient is typically measured at very low pressure $(<0.1 \mathrm{~atm})$ which is not representative of the thermodynamic conditions of the TPD experiment. Several studies ${ }^{22,90-91}$ put forward that for $\operatorname{Pt}(111)$ surface, the $\mathrm{O}_{2}$ sticking coefficient lies around $10^{-2}$. For $\operatorname{Pt}(111)$ stepped surfaces, ${ }^{101-102}$ the coefficients were higher and around $10^{-1}$ but the sites were quickly saturated. Considering the peculiar structure of $\mathrm{Pt}_{13}$ cluster, we varied the sticking coefficient of $\mathrm{O}_{2}$ from 1 to $10^{-6}$. Even though the sticking coefficient is expected to decrease with $\theta_{\mathrm{O}}$, it was assumed to be independent of oxygen coverage, for the sake of simplying the analysis of its impact on desorption. According to the present model, the first two $\mathrm{O}_{2}$ peaks start to merge for sticking probabilities lower than the threshold value of $10^{-2}$ (Figure 12-b). A slight shift towards higher temperatures is observed for the last peak.

The estimation of enthalpies and entropies from ab initio calculations can also lead to an error for methodological reasons. To estimate the consequences of typical errors, we built two kinetic models that lower or enhance the reactivity. The sticking coefficient of $\mathrm{O}_{2}$ was set to 1 . The model

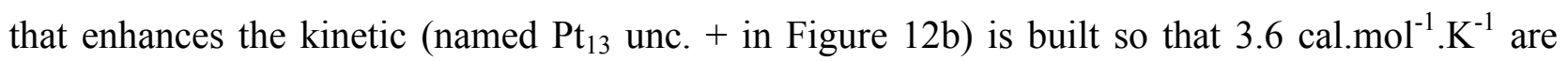
added to each $\Delta_{r} S_{\text {desorption }}$ and $3.6 \mathrm{kcal} . \mathrm{mol}^{-1}$ are removed to $\mathrm{E}_{\text {dissociation }}$ and $\Delta_{r} H_{\text {desorption }}$. In that 
case a $60^{\circ} \mathrm{C}$ peak shift is noticed. The $\mathrm{Pt}_{13}$ unc. - model displays two merged peaks at low temperature and a $70^{\circ} \mathrm{C}$ shift to higher temperatures.

From our analyses, one can conclude that all desorptions are simulated above $500^{\circ} \mathrm{C}$ with the $\mathrm{Pt}_{13}$ model, in line with the highest temperature peaks recorded experimentally for both $1 \%$ and $0.3 \% \mathrm{Pt} / \gamma-\mathrm{Al}_{2} \mathrm{O}_{3}$ ultra-dispersed catalysts. The lower temperature peaks are better explained by our $\operatorname{Pt}(111)$ ab initio kinetic model, suggesting that the biggest particles are at the origin of these peaks. Accordingly, they were shown to be more abundant on the $1 \% \mathrm{Pt} / \gamma-\mathrm{Al}_{2} \mathrm{O}_{3}$ catalyst (Figure

\subsection{Reaction paths analyses}

As the current model is able to reproduce TPD experiment correctly at high temperatures, we may perform path analyses to interpret the model behaviour at high temperatures. The logarithm of the rate constants taken at the temperature of the peaks are reported in Figure 13a. It shows that the preferential path goes through $\mathrm{Pt}_{13} \mathrm{O}_{16-\mathrm{TL}}$ that is the predominant structure between $630^{\circ} \mathrm{C}$ and $810^{\circ} \mathrm{C}$. The rate constants are sufficiently high to desorb more oxygen via the reaction between $\mathrm{Pt}_{13} \mathrm{O}_{16-\mathrm{HM}}$ and $\mathrm{Pt}_{13} \mathrm{O}_{14-\mathrm{HM}}$. The preferred path engages then both $\mathrm{Pt}_{13} \mathrm{O}_{14-\mathrm{TL}}$ and $\mathrm{Pt}_{13} \mathrm{O}_{14-\mathrm{HM}}$ to $\mathrm{Pt}_{13} \mathrm{O}_{12}$. 

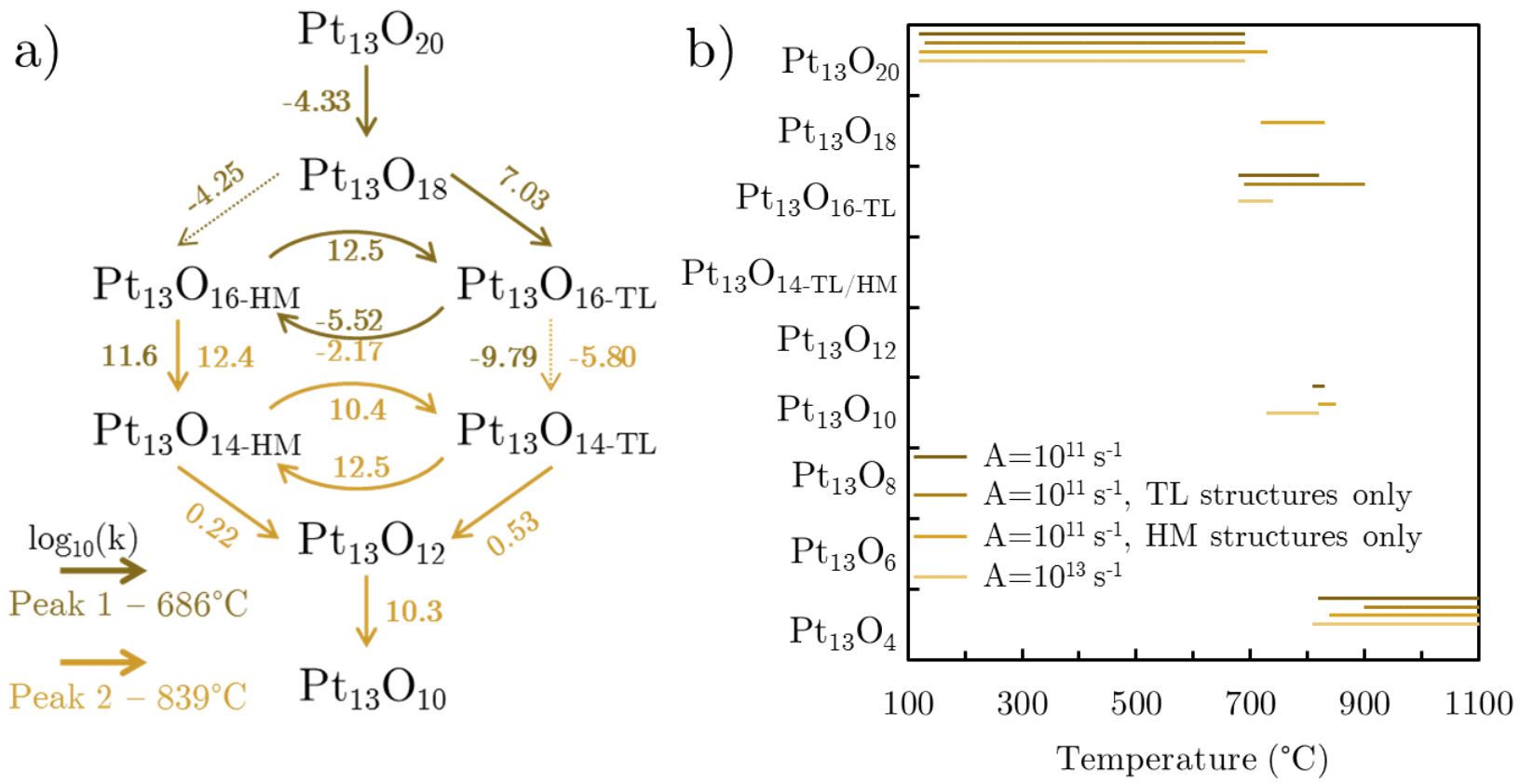

Figure 13 : (a) Logarithm of the rate constants (in $\mathrm{s}^{-1}$ ) at the peak temperature for $\mathrm{Pt}_{13} \mathrm{O}_{\mathrm{n}}$ kinetic mechanism. The sticking coefficient of $\mathrm{O}_{2}$ is $10^{-2}$. (b) Predominant surface species during TPD experiments with distinct scheme structure. The impact of the pre-exponential factor of the two surface reaction $\mathrm{A}$ is studied as well as the two paths involving $\mathrm{Pt}_{13} \mathrm{O}_{\mathrm{n}-\mathrm{TL}}$ or $\mathrm{Pt}_{13} \mathrm{O}_{\mathrm{n}-\mathrm{HM}}$ independently. The sticking coefficient of $\mathrm{O}_{2}$ is $10^{-2}$. The reference scheme is the darker one.

The pre-exponential parameters of $\mathrm{Pt}_{13} \mathrm{O}_{22}$ reduction to $\mathrm{Pt}_{13} \mathrm{O}_{20}$ appear by far as the most important ones for $\mathrm{O}_{2}$ concentration prediction, the sensitivity being 40 times higher than that of the $\mathrm{Pt}_{13} \mathrm{O}_{18}$ to $\mathrm{Pt}_{13} \mathrm{O}_{16}$ - $\mathrm{HM}$ reaction. This sensitivity is however significant only between $310^{\circ} \mathrm{C}$ and $380^{\circ} \mathrm{C}$, before the first desorption peak occurs. This suggests that some $\mathrm{Pt}_{13} \mathrm{O}_{22}$ may appear at low temperature and desorbs at lower temperature than the first observed peak.

In order to evaluate the impact of the four structures for $n=14$ and 16 , the TPD was predicted with only TL structures or HM structures using two distinct schemes. The predominant species are displayed in Figure 13b, as a function of the temperature. First and foremost, the major species 
remains $\mathrm{Pt}_{13} \mathrm{O}_{20}$ up to the same temperature for the common scheme and the TL one. The 2 desorption of $\mathrm{O}_{2}$ from this species is predicted to occur at higher temperature for HM model than for TL model. While the TM model proceeds mainly through $\mathrm{Pt}_{13} \mathrm{O}_{16-\mathrm{TL}}$, the $\mathrm{HM}$ scheme predicts a direct desorption from $\mathrm{Pt}_{13} \mathrm{O}_{18}$ to $\mathrm{Pt}_{13} \mathrm{O}_{10}$. Moreover the pre-exponential factor set for the surface reactions has a very modest impact on $\mathrm{O}_{2}$ release and does not induce any variation in the scheme path.

Finally, one may compare the stability domains given by the kinetic model (Figure 13b) and from the $a b$ initio thermodynamic diagram (Figure 7). Trying to depict the species appearing in the course of the TPD by a single $\mathrm{O}_{2}$ partial pressure and by an equilibrium situation is not possible, as we should have a large kinetic stability domain for $\mathrm{Pt}_{13} \mathrm{O}_{8}$ in any case, before reaching $\mathrm{Pt}_{13} \mathrm{O}_{4}$. This shows that kinetic limitations play a strong role in TPD, which cannot be described by a simple thermodynamic diagram.

Considering the temperature ranges of $\mathrm{O}_{2}$ desorption, the multi-scale approach which relies on $a b$ initio calculations for microkinetic model development provides a consistent model. In addition, the kinetic analyses offers an unrivalled mean to interpret the features of the experimental $\mathrm{O}_{2}$-TPD. It highlights the effect of complex systems involving different cluster geometries which tends to be more realistic. In addition, the kinetic analysis demonstrates that both cluster morphologies (two-layers and hemispherical) must be considered for $\mathrm{O}_{2}$ desorption. 


\section{Conclusion}

In the present work, we have presented a multi-scale approach applied to oxygen adsorption on highly dispersed $\mathrm{Pt} / \gamma-\mathrm{Al}_{2} \mathrm{O}_{3}$, combining TPD experiments, ab initio and kinetic modeling. High temperature desorption was observed experimentally, suggesting that much stronger interactions exist between oxygen and $\mathrm{Pt}_{13}$ clusters than for extended surfaces. The ab initio electronic calculations of a 13-platinum cluster supported on alumina shows that the support is involved for the most stable adsorption sites. A morphology change is observed according to oxygen coverage, with a low coverage structure characterized by two parallel layers of platinum and an hemispherical shape at high coverage. Ab initio thermodynamic data allows to build a phase diagram that shows a highly oxidized cluster for accessible $\mathrm{O}_{2}$ pressure and temperature. The same study was applied to the $\operatorname{Pt}(111)$ surface. Kinetic schemes were then set up to simulate TPD experiments using $\mathrm{Pt}_{13}$ and $\mathrm{Pt}(111)$ ab initio simulated thermokinetic parameters. Despite some uncertainties on sticking coefficient and desorption free energy barriers, the two models suggest that the experimental low temperature desorption is in agreement with some peak of the $\operatorname{Pt}(111)$ simulated TPD, characteristic of large particle with regular facets, whereas high temperature desorption is clearly the contribution of small platinum particles.

Finally this work highlights the reactivity of highly dispersed platinum supported on alumina. Several computed thermochemical data such as the heat of adsorption and the achievable oxygen coverage thoroughly differ from well-known extended surfaces. The temperature-programmed desorption of $\mathrm{O}_{2}$ and the related kinetic simulations demonstrate similar desorption temperature ranges that again consolidate the approach of coupling the experimental and modeling work. The model established herein could be implemented in the future for highly dispersed platinum 
catalysis mechanism in oxidant media, such as oxidation of carbon monoxide into $\mathrm{CO}_{2}$. Some in2 depth work would be needed regarding kinetic parameters such as the sticking probability. Also it is shown that a special attention has to be made to account for the structural dimension of modeled systems and its translation in the kinetic scheme. Yet complex $a b$ initio models, including a support, an anisotropic catalyst structure and a large oxygen coverage range among others, are herein shown to be relevant when integrated in a kinetic scheme according to the conducted $\mathrm{O}_{2-}$ TPD experiments.

$7 \quad$ TPD experiments.

\section{ASSOCIATED CONTENT}

Supporting Information contains: illustration of a typical velocity-scaled MD run with cluster reconstruction; estimation of the Gibbs free energy of adsorption; X-Ray fluorescence a for the two catalysts; optimization of the TPD protocol; deconvolution of the TPD profiles; dissociative adsorption of $\mathrm{O}_{2}$ on $\mathrm{Pt}(111)$ investigated by ab initio calculations; most stable structures found for the supported $\mathrm{Pt}_{13} \mathrm{O}_{\mathrm{n}}$ system from ab initio calculations; transition structures for the dissociation of $\mathrm{O}_{2}$; kinetic parameters for the $\mathrm{Pt}_{13} \mathrm{O}_{\mathrm{n}}$ model and $\mathrm{Pt}(111)$ model.

\section{ACKNOWLEDGMENT}

The authors thank C. Guegan and F. Diehl (Catalysis and Separation Division, IFP Energies nouvelles) for providing the $\mathrm{Pt} / \gamma-\mathrm{Al}_{2} \mathrm{O}_{3}$ catalysts, and $\mathrm{O}$. Gardoll for help in the TPD experiments undertook at UCCS laboratory at Villeneuve d'Ascq, France. All ab initio calculations were performed on the ENER110 supercomputer at IFP Energies nouvelles. 
Notes

2

The authors declare no competing financial interest.

Corresponding Author note.

Céline Chizallet, celine.chizallet@,ifpen.fr 
(1) Bell, A. T., The Impact of Nanoscience on Heterogeneous Catalysis, Science 2003, 299, 1688-1691.

(2) Gates, B. C., Supported Metal Clusters: Synthesis, Structure, and Catalysis, Chem. Rev. 1995, 95, 511-522.

(3) Chen, A.; Holt-Hindle, P., Platinum-Based Nanostructured Materials: Synthesis, Properties, and Applications, Chem. Rev. 2010, 110, 3767-3804.

(4) Sun, G.; Sautet, P., Metastable Structures in Cluster Catalysis from First-Principles: Structural Ensemble in Reaction Conditions and Metastability Triggered Reactivity, J. Am. Chem. Soc. 2018, 140, 2812-2820.

(5) Sattler, J. J.; Ruiz-Martinez, J.; Santillan-Jimenez, E.; Weckhuysen, B. M., Catalytic Dehydrogenation of Light Alkanes on Metals and Metal Oxides, Chem. Rev. 2014, 114, 10613-10653.

(6) Avenier, P.; Bazer-Bachi, D.; Bazer-Bachi, F.; Chizallet, C.; Deleau, F.; Diehl, F.; Gornay, J.; Lemaire, É.; Moizan-Basle, V.; Plais, C.et al, Catalytic Reforming: Methodology and Process Development for a Constant Optimisation and Performance Enhancement, Oil Gas Sci. Technol. - Rev. IFPEN 2016, 71, 41-59.

(7) Burch, R., Knowledge and Know-How in Emission Control for Mobile Applications, Catal. Rev. 2004, 46, 271-334.

(8) Sinfelt, J. H.,Catalytic reforming, In Handbook of Heterogeneous Catalysis; Ertl, G., Knözinger, E., Weitkamp, J., Eds.; Wiley: Weinheim, 1997, p 1939-1955.

(9) Russell, A.; Epling, W. S., Diesel Oxidation Catalysts, Catal. Rev. 2011, 53, 337-423.

(10) Morozan, A.; Jousselme, B.; Palacin, S., Low-Platinum and Platinum-Free Catalysts for the Oxygen Reduction Reaction at Fuel Cell Cathodes, Energy Environ. Sci. 2011, 4, 1238-1254.

(11) Gasteiger, H. A.; Kocha, S. S.; Sompalli, B.; Wagner, F. T., Activity Benchmarks and Requirements for Pt, Pt-Alloy, and non-Pt Oxygen Reduction Catalysts for PEMFCs, Appl. Catal. B 2005, 56, 9-35.

(12) Lykhach, Y.; Bruix, A.; Fabris, S.; Potin, V.; Matolinova, I.; Matolin, V.; Libuda, J.; Neyman, K. M., OxideBased Nanomaterials for Fuel Cell Catalysis: the Interplay between Supported Single Pt Atoms and Particles, Catal. Sci. Technol. 2017, 7, 4315-4345.

(13) Marković, N. M.; Schmidt, T. J.; Stamenković, V.; Ross, P. N., Oxygen Reduction Reaction on Pt and Pt Bimetallic Surfaces: A Selective Review, Fuel Cells 2001, 1, 105-116.

(14) Critical raw materials for the EU, European Commission, 2010.

(15) Roduner, E., Size Matters: why Nanomaterials are Different, Chem. Soc. Rev. 2006, 35, 583-592.

(16) Roldan Cuenya, B.; Behafarid, F., Nanocatalysis: size- and shape-dependent chemisorption and catalytic reactivity, Surf. Sci. Rep. 2015, 70, 135-187.

(17) Zhai, H.; Alexandrova, A. N., Fluxionality of Catalytic Clusters: When It Matters and How to Address It, ACS Catal. 2017, 7, 1905-1911.

(18) García-Diéguez, M.; Chin, Y.-H.; Iglesia, E., Catalytic Reactions of Dioxygen with Ethane and Methane on Platinum Clusters: Mechanistic Connections, Site Requirements, and Consequences of Chemisorbed Oxygen, $J$. Catal. 2012, 285, 260-272.

(19) Weaver, J. F.; Chen, J.-J.; Gerrard, A. L., Oxidation of Pt(111) by Gas-Phase Oxygen Atoms, Surf. Sci. 2005, 592, 83-103.

(20) Légaré, P., Interaction of Oxygen with the Pt(111) Surface in Wide Conditions Range. A DFT-Based Thermodynamical Simulation, Surf. Sci. 2005, 580, 137-144.

(21) Pang, Q.; Zhang, Y.; Zhang, J.-M.; Xu, K.-W., Structural and Electronic Properties of Atomic Oxygen Adsorption on Pt(111): A Density-Functional Theory Study, Appl. Surf. Sci. 2011, 257, 3047-3054.

(22) Campbell, C. T.; Ertl, G.; Kuipers, H.; Segner, J., A Molecular Beam Study of the Adsorption and Desorption of Oxygen from a Pt(111) Surface, Surf. Sci. 1981, 107, 220-236.

(23) Elg, A.-P.; Eisert, F.; Rosén, A., The Temperature Dependence of the Initial Sticking Probability of Oxygen on Pt(111) Probed with Second Harmonic Generation, Surf. Sci. 1997, 382, 57-66.

(24) Hwang, C.-P.; Yeh, C.-T., Platinum-Oxide Species Formed by Oxidation of Platinum Crystallites Supported on Alumina, J. Mol. Catal. A 1996, 112, 295-302. 
(25) Salmerón, M.; Brewer, L.; Somorjai, G. A., The Structure and Stability of Surface Platinum Oxide and of Oxides of Other Noble Metals, Surf. Sci. 1981, 112, 207-228.

(26) Fantauzzi, D.; Mueller, J. E.; Sabo, L.; van Duin, A. C.; Jacob, T., Surface Buckling and Subsurface Oxygen: Atomistic Insights into the Surface Oxidation of Pt(111), ChemPhysChem 2015, 16, 2797-2802.

(27) Krasnikov, S. A.; Murphy, S.; Berdunov, N.; McCoy, A. P.; Radican, K.; Shvets, I. V., Self-Limited Growth of Triangular $\mathrm{PtO}_{2}$ Nanoclusters on the Pt(111) Surface, Nanotechnology 2010, 21, 335301.

(28) Devarajan, S. P.; Hinojosa, J. A.; Weaver, J. F., STM Study of High-Coverage Structures of Atomic Oxygen on Pt(111): p(2×1) and Pt Oxide Chain Structures, Surf. Sci. 2008, 602, 3116-3124.

(29) van Spronsen, M. A.; Frenken, J. W. M.; Groot, I. M. N., Observing the Oxidation of Platinum, Nat. Commun. 2017, 8, 429.

(30) Bray, J. M.; Smith, J. L.; Schneider, W. F., Coverage-Dependent Adsorption at a Low Symmetry Surface: DFT and Statistical Analysis of Oxygen Chemistry on Kinked Pt(321), Topics Catal. 2014, 57, 89-105.

(31) Jenkins, S. J.; Petersen, M. A.; King, D. A., Comparative theory of missing-row reconstructions: Pt $\{110\}$, Pt $\{211\}$ and Pt $\{311\}$, Surf. Sci. 2001, 494, 159-165.

(32) Carlsson, P.-A.; Mollner, S.; Arnby, K.; Skoglundh, M., Effect of Periodic Operation on the Low-

Temperature Activity for Propane Oxidation over Pt/ $/ \mathrm{Al}_{2} \mathrm{O}_{3}$ catalysts, Chem. Eng. Sci. 2004, 59, 4313-4323.

(33) Yazawa, Y.; Yoshida, H.; Hattori, T., The Support Effect on Platinum Catalyst under Oxidizing Atmosphere: Improvement in the Oxidation-Resistance of Platinum by the Electrophilic Property of Support Materials, Appl.

Catal. A 2002, 237, 139-148.

(34) Wang, C.-B.; Yeh, C.-T., Effects of Particle Size on the Progressive Oxidation of Nanometer Platinum by Dioxygen, J. Catal. 1998, 178, 450-456.

(35) Shelimov, B.; Lambert, J.-F.; Che, M.; Didillon, B., Application of NMR to Interfacial Coordination Chemistry: A ${ }^{195} \mathrm{Pt}$ NMR Study of the Interaction of Hexachloroplatinic Acid Aqueous Solutions with Alumina, J. Am. Chem. Soc. 1999, 121, 545-556.

(36) Gruber, H. L., Chemisorption Studies on Supported Platinum, J. Phys. Chem. 1962, 66, 48-54.

(37) O'Rear, D. J.; Löffler, D. G.; Boudart, M., Stoichiometry of the Titration by Dihydrogen of Oxygen

Adsorbed on Platinum, J. Catal. 1990, 121, 131-140.

(38) Vannice, M. A.; Benson, J. E.; Boudart, M., Determination of Surface Area by Chemisorption: Unsupported Platinum, J. Catal. 1970, 16, 348-356.

(39) Boudart, M., Catalysis by Supported Metals, Adv. Catal. 1969, 20, 153-166.

(40) Euzen, P.; Raybaud, P.; Krokidis, X.; Toulhoat, H.; Loarer, J. L.; Jolivet, J.-P.; Froidefond, C.,Alumina, In Handbook of Porous Solids; Schüth, F., Sing, K. S. W., Weitkamp, J., Eds.; Wiley-VCH: Weinheim, 2002.

(41) Gorczyca, A.; Moizan, V.; Chizallet, C.; Proux, O.; Del Net, W.; Lahera, E.; Hazemann, J. L.; Raybaud, P.; Joly, Y., Monitoring Morphology and Hydrogen Coverage of Nanometric Pt/Gamma- $\mathrm{Al}_{2} \mathrm{O}_{3}$ Particles by in situ HERFD-XANES and Quantum Simulations, Angew. Chem., Int. Ed. 2014, 53, $12426-12429$.

(42) Kwak, J. H.; Hu, J.; Mei, D.; Yi, C. W.; Kim, D. H.; Peden, C. H. F.; Allard, L. F.; Szanyi, J., Coordinatively Unsaturated $\mathrm{Al}^{3+}$ Centers as Binding Sites for Active Catalyst Phases of Platinum on Gamma- $\mathrm{Al}_{2} \mathrm{O}_{3}$, Science 2009, 325, 1670-1673.

(43) Nellist, P. D.; Pennycook, S. J., Direct Imaging of the Atomic Configuration of Ultradispersed Catalysts, Science 1996, 274, 413-415.

(44) Sinkler, W.; Sanchez, S. I.; Bradley, S. A.; Wen, J.; Mishra, B.; Kelly, S. D.; Bare, S. R., AberrationCorrected Transmission Electron Microscopy and In Situ XAFS Structural Characterization of $\mathrm{Pt} / \gamma-\mathrm{Al}_{2} \mathrm{O}_{3}$ Nanoparticles, ChemCatChem 2015, 7, 3779-3787.

(45) Raybaud, P.; Chizallet, C.; Mager-Maury, C.; Digne, M.; Toulhoat, H.; Sautet, P., From Gamma-Alumina to Supported Platinum Nanoclusters in Reforming Conditions: 10 years of DFT Modeling and Beyond, J. Catal. 2013, 308, 328-340.

(46) Chizallet, C.; Raybaud, P., Density Functional Theory Simulations of Complex Catalytic Materials in Reactive Environments: Beyond the Ideal Surface at Low Coverage, Catal. Sci. Technol. 2014, 4, 2797-2813. 
(47) Trinchero, A.; Klacar, S.; Paz-Borbón, L. O.; Hellman, A.; Grönbeck, H., Oxidation at the Subnanometer Scale, J. Phys. Chem. C 2015, 119, 10797-10803.

(48) Zhang, W.; Sumer, A.; Jellinek, J.; Cheng, D., Morphology Tailoring of Pt Nanocatalysts for the Oxygen Reduction Reaction: The Paradigm of $\mathrm{Pt}_{13}$, ChemNanoMat 2015, 1, 482-488.

(49) Xu, Y.; Shelton, W. A.; Schneider, W. F., Effect of Particle Size on the Oxidizability of Platinum Clusters, $J$. Phys. Chem. A 2006, 110, 5839-5846.

(50) Xu, Y.; Shelton, W. A.; Schneider, W. F., Thermodynamic Equilibrium Compositions, Structures, and Reaction Energies of $\mathrm{Pt}_{\mathrm{x}} \mathrm{O}_{\mathrm{y}}(\mathrm{x}=1-3)$ Clusters Predicted from First Principles, J. Phys. Chem. B 2006, 110, 16591-16599.

(51) Jennings, P. C.; Aleksandrov, H. A.; Neyman, K. M.; Johnston, R. L., A DFT Study of Oxygen Dissociation on Platinum based Nanoparticles, Nanoscale 2014, 6, 1153-1165.

(52) Hu, C. H.; Chizallet, C.; Toulhoat, H.; Raybaud, P., Structural, Energetic, and Electronic Trends in LowDimensional Late-Transition-Metal Systems, Phys. Rev. B 2009, 79, 195416.

(53) Hu, C. H.; Chizallet, C.; Mager-Maury, C.; Corral Valero, M.; Sautet, P.; Toulhoat, H.; Raybaud, P., Modulation of Catalyst Particle Structure upon Support Hydroxylation: Ab Initio Insights for $\mathrm{Pd}_{13}$ and $\mathrm{Pt}_{13} /$ Gamma- $\mathrm{Al}_{2} \mathrm{O}_{3}, J$. Catal. 2010, 274, 99-110.

(54) Li, L.; Larsen, A. H.; Romero, N. A.; Morozov, V. A.; Glinsvad, C.; Abild-Pedersen, F.; Greeley, J.; Jacobsen, K. W.; Norskov, J. K., Investigation of Catalytic Finite-Size-Effects of Platinum Metal Clusters, $J$. Phys. Chem. Lett. 2013, 4, 222-226.

(55) Holby, E. F.; Greeley, J.; Morgan, D., Thermodynamics and Hysteresis of Oxide Formation and Removal on Platinum (111) Surfaces, J. Phys. Chem. C 2012, 116, 9942-9946.

(56) Fu, Q.; Yang, J.; Luo, Y., A First Principles Study on the Dissociation and Rotation Processes of a Single $\mathrm{O}_{2}$ Molecule on the Pt(111) Surface, J. Phys. Chem. C 2011, 115, 6864-6869.

(57) Watwe, R. M.; Cortright, R. D.; Mavrikakis, M.; Norskov, J. K.; Dumesic, J. A., Density Functional Theory Studies of the Adsorption of Ethylene and Oxygen on $\mathrm{Pt}(111)$ and $\mathrm{Pt}_{3} \mathrm{Sn}(111)$, J. Chem. Phys. 2001, 114, 46634668 .

(58) Bray, J. M.; Skavdahl, I. J.; McEwen, J. S.; Schneider, W. F., First-Principles Reaction Site Model for Coverage-Sensitive Surface Reactions: Pt(111)-O Temperature Programmed Desorption, Surf. Sci. 2014, 622, L1-L6.

(59) Zhu, T.; Sun, S.-G.; van Santen, R. A.; Hensen, E. J. M., Reconstruction of Clean and Oxygen-Covered Pt(110) Surfaces, J. Phys. Chem. C 2013, 117, 11251-11257.

(60) Liu, D. J.; Evans, J. W., Interactions Between Oxygen Atoms on Pt(100): Implications for Ordering during Chemisorption and Catalysis, ChemPhysChem 2010, 11, 2174-2181.

(61) Nguyen, T. Q.; Escaño, M. C. S.; Nakanishi, H.; Kasai, H.; Maekawa, H.; Osumi, K.; Sato, K., DFT+U Study on the Oxygen Adsorption and Dissociation on $\mathrm{CeO}_{2}$-Supported Platinum Cluster, Appl. Surf. Sci. 2014, 288, 244-250.

(62) Wang, X.; van Bokhoven, J. A.; Palagin, D., Ostwald Ripening versus Single Atom Trapping: towards Understanding Platinum Particle Sintering, Phys. Chem. Chem. Phys. 2017, 19, 30513-30519.

(63) Mager-Maury, C.; Bonnard, G.; Chizallet, C.; Sautet, P.; Raybaud, P., $\mathrm{H}_{2}$-Induced Reconstruction of Supported Pt Clusters: Metal-Support Interaction versus Surface Hydride, ChemCatChem 2011, 3, 200-207. (64) Saeys, M.; Reyniers, M.-F.; Thybaut, J. W.; Neurock, M.; Marin, G. B., First-Principles Based Kinetic Model for the Hydrogenation of Toluene, J. Catal. 2005, 236, 129-138.

(65) Salciccioli, M.; Stamatakis, M.; Caratzoulas, S.; Vlachos, D. G., A Review of Multiscale Modeling of MetalCatalyzed Reactions: Mechanism Development for Complexity and Emergent Behavior, Chem. Eng. Sci. 2011, 66, 4319-4355.

(66) Reuter, K., Ab Initio Thermodynamics and First-Principles Microkinetics for Surface Catalysis, Catal. Lett. 2016, 146, 541-563. 
1 (67) Sabbe, M. K.; Canduela-Rodriguez, G.; Joly, J.-F.; Reyniers, M.-F.; Marin, G. B., Ab Initio Coverage-

2 Dependent Microkinetic Modeling of Benzene Hydrogenation on Pd(111), Catal. Sci. Technol. 2017, 7, 5267-

35283.

(68) John, M.; Alexopoulos, K.; Reyniers, M.-F.; Marin, G. B., Effect of Zeolite Confinement on the Conversion of 1-Butanol to Butene Isomers: Mechanistic Insights from DFT Based Microkinetic Modelling, Catal. Sci.

Technol. 2017, 7, 2978-2997.

(69) Larmier, K.; Chizallet, C.; Maury, S.; Cadran, N.; Abboud, J.; Lamic-Humblot, A. F.; Marceau, E.; LauronPernot, H., Isopropanol Dehydration on Amorphous Silica-Alumina: Synergy of Bronsted and Lewis Acidities at Pseudo-Bridging Silanols, Angew. Chem. Int. Ed. 2017, 56, 230-234.

(70) Larmier, K.; Nicolle, A.; Chizallet, C.; Cadran, N.; Maury, S.; Lamic-Humblot, A.-F.; Marceau, E.; LauronPernot, H., Influence of Coadsorbed Water and Alcohol Molecules on Isopropyl Alcohol Dehydration on $\gamma^{-}$ Alumina: Multiscale Modeling of Experimental Kinetic Profile, ACS Catal. 2016, 6, 1905-1920.

(71) Rankovic, N.; Chizallet, C.; Nicolle, A.; Da Costa, P., Multiscale Modeling of Barium Sulfate Formation from $\mathrm{BaO}$, Ind. Eng. Chem. Res. 2013, 52, 9086-9098.

(72) Sabbe, M. K.; Reyniers, M.-F.; Reuter, K., First-Principles Kinetic Modeling in Heterogeneous Catalysis: an Industrial Perspective on Best-Practice, Gaps and Needs, Catal. Sci. Technol. 2012, 2, 2010-2024.

(73) Maestri, M., Escaping the trap of complication and complexity in multiscale microkinetic modelling of heterogeneous catalytic processes, Chem. Commun. 2017, 53, 10244-10254.

(74) Jasper, A. W.; Pelzer, K. M.; Miller, J. A.; Kamarchik, E.; Harding, L. B.; Klippenstein, S. J., Predictive a Priori Pressure-Dependent Kinetics, Science 2014, 346, 1212-1215.

(75) Mao, Y.; Wang, H.-F.; Hu, P., Theory and Applications of Surface Micro-Kinetics in the Rational Design of Catalysts using Density Functional Theory Calculations, Wiley Interdisciplinary Reviews: Computational Molecular Science 2017, 7, e1321.

(76) Kresse, G.; Hafner, J., Ab Initio Molecular-Dynamics Simulation of the Liquid-Metal-AmorphousSemiconductor Transition in Germanium, Phys. Rev. B 1994, 49, 14251-14269.

(77) Kresse, G.; Furthmüller, J., Efficiency of Ab-Initio Total Energy Calculations for Metals and Semiconductors using a Plane-Wave Basis Set, Comput. Mat. Sci. 1996, 6, 15-50.

(78) Kresse, G.; Joubert, D., From Ultrasoft Pseudopotentials to the Projector Augmented-Wave Method, Phys. Rev. B 1999, 59, 1758-1775.

(79) Perdew, J.; Burke, K.; Ernzerhof, M., Generalized Gradient Approximation Made Simple, Phys. Rev. Lett. 1996, 77, 3865-3868.

(80) Sanville, E.; Kenny, S. D.; Smith, R.; Henkelman, G., Improved Grid-Based Algorithm for Bader Charge Allocation, J. Comput. Chem. 2007, 28, 899-908.

(81) Henkelman, G.; Arnaldsson, A.; Jonsson, H., A Fast and Robust Algorithm for Bader Decomposition of Charge Density, Comput. Mat. Sci. 2006, 36, 354-360.

(82) Digne, M.; Sautet, P.; Raybaud, P.; Euzen, P.; Toulhoat, H., Hydroxyl Groups on Gamma-Alumina Surfaces: a DFT Study, J. Catal. 2002, 211, 1-5.

(83) Digne, M.; Sautet, P.; Raybaud, P.; Euzen, P.; Toulhoat, H., Use of DFT to Achieve a Rational Understanding of Acid-Basic Properties of Gamma-Alumina Surfaces, J. Catal. 2004, 226, 54-68.

(84) Jahel, A.; Moizan-Baslé, V.; Chizallet, C.; Raybaud, P.; Olivier-Fourcade, J.; Jumas, J. C.; Avenier, P.; Lacombe, S., Effect of Indium-Doping of Gamma-Alumina on the Stabilization of PtSn Alloy Clusters Prepared by Surface Organostannic Chemistry, J. Phys. Chem. C 2012, 116, 10073-10083.

(85) Henkelman, G.; Jonsson, H., Improved Tangent Estimate in the Nudged Elastic Band Method for Finding Minimum Energy Paths and Saddle Points, J. Chem. Phys. 2000, 113, 9978-9985.

(86) Fleurat-Lessard, P.; Dayal, P., http://pfleurat.free.fr/ReactionPath.php, Accessed April $2^{\text {nd }} 2016$.

(87) Pulay, P., Convergence Acceleration of Iterative Sequences. The Case of SCf Iteration, Chem. Phys. Lett. 1980, 73, 393-398.

(88) CHEMKIN-PRO 15131, Reaction Design, San Diego, CA, 2013. 
(89) Keppeler, M.; Bräuning, G.; Radhakrishnan, S. G.; Liu, X.; Jensen, C.; Roduner, E., Reactivity of Diatomics and of Ethylene on Zeolite-Supported 13-Atom Platinum Nanoclusters, Catal. Sci. Technol. 2016, 6, 6814-6823. (90) Hopster, H.; Ibach, H.; Comsa, G., Catalytic Oxidation of Carbon Monoxide on Stepped Platinum(111) Surfaces, J. Catal. 1977, 46, 37-48.

(91) Bonzel, H. P.; Ku, R., On the Kinetics of Oxygen Adsorption on a Pt(111) Surface, Surf. Sci. 1973, 40, 85101.

(92) Lagauche, M.; Larmier, K.; Jolimaitre, E.; Barthelet, K.; Chizallet, C.; Favergeon, L.; Pijolat, M., Thermodynamic Characterization of the Hydroxyl Group on the $\gamma$-Alumina Surface by the Energy Distribution Function, J. Phys. Chem. C 2017, 121, 16770-16782.

(93) Parker, D. H.; Bartram, M. E.; Koel, B. E., Study of High Coverages of Atomic Oxygen on the Pt(111) Surface, Surf. Sci. 1989, 217, 489-510.

(94) Badan, C.; Farber, R. G.; Heyrich, Y.; Koper, M. T. M.; Killelea, D. R.; Juurlink, L. B. F., Step-Type Selective Oxidation of Platinum Surfaces, J. Phys. Chem. C 2016, 120, 22927-22935.

(95) Olsson, L.; Westerberg, B.; Persson, H.; Fridell, E.; Skoglundh, M.; Andersson, B., A Kinetic Study of Oxygen Adsorption/Desorption and NO Oxidation over $\mathrm{Pt} / \mathrm{Al}_{2} \mathrm{O}_{3}$ Catalysts, J. Phys. Chem. B 1999, 103, 10433 10439.

(96) Mihai, O.; Creaser, D.; Olsson, L., Adsorption and Oxidation Investigations over $\mathrm{Pt} / \mathrm{Al}_{2} \mathrm{O}_{3}$ Catalyst: A Microcalorimetric Study, Catalysts 2016, 6, 73.

(97) Wartnaby, C. E.; Stuck, A.; Yeo, Y. Y.; King, D. A., Microcalorimetric Heats of Adsorption for CO, NO, and Oxygen on Pt $\{110\}$, J. Phys. Chem. 1996, 100, 12483-12488.

(98) Boudart, M.; Aldag, A.; Benson, J. E.; Dougharty, N. A.; Girvin Harkins, C., On the Specific Activity of Platinum Catalysts, J. Catal. 1966, 6, 92-99.

(99) Dumesic, J. A.; Rudd, D. F.; Aparicio, L. M.; Rekoske, J. E.; Trevino, A. A. The Microkinetics of Heterogeneous Catalysis; American Chemical Society: Washington DC, 1993.

(100) Deutschmann, O.; Behrendt, F.; Warnatz, J., Modelling and Simulation of Heterogeneous Oxidation of Methane on a Platinum Foil, Catal. Today 1994, 21, 461-470.

(101) Gland, J. L.; Korchak, V. N., The Adsorption of Oxygen on a Stepped Platinum Single Crystal Surface, Surf. Sci. 1978, 75, 733-750.

(102) Schwaha, K.; Bechtold, E., The adsorption of oxygen on the stepped Pt(S)-[9(111) $\times(111)]$ face, Surf. Sci. 1977, 65, 277-286. 


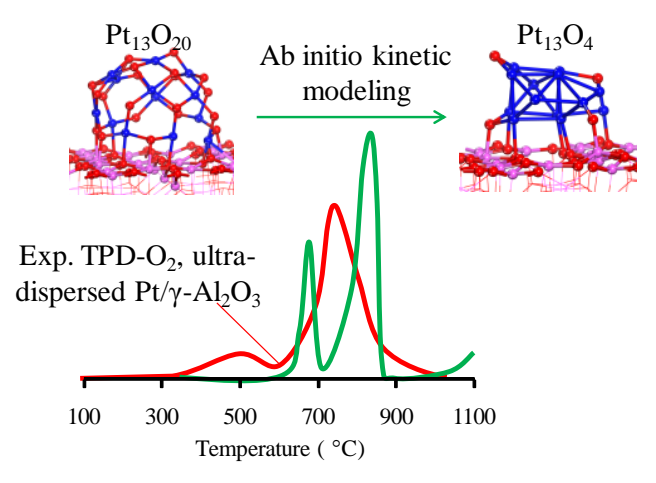

